\title{
Tropical Cumulus Convection and Upward-Propagating Waves in Middle-Atmospheric GCMs
}

\author{
T. Horinouchi,${ }^{a}$ S. Pawson,,${ }^{\mathrm{b}, \mathrm{c}}$ K. Shibata,${ }^{\mathrm{d}}$ U. Langematz, ${ }^{\mathrm{e}}$ E. Manzini,${ }^{\mathrm{f}, \mathrm{g}}$ M. A. Giorgetta, ${ }^{\mathrm{f}}$ F. Sassi, ${ }^{\mathrm{h}}$ \\ R. J. Wilson, ${ }^{\mathrm{i}}$ K. Hamilton,${ }^{\mathrm{j}} \mathrm{J}$. De Grandpré,${ }^{\mathrm{k}}$ And A. A. Scaife ${ }^{\mathrm{l}}$ \\ ${ }^{a}$ Radio Science Center for Space and Atmosphere, Kyoto University, Uji, Japan \\ ${ }^{b}$ Data Assimilation Office, NASA GSFC, Greenbelt, Maryland \\ ${ }^{c}$ Goddard Earth Sciences and Technology Center, University of Maryland, Baltimore County, Baltimore, Maryland \\ ${ }^{d}$ Meteorological Research Institute, Tsukuba, Japan \\ ${ }^{e}$ Freie Universität Berlin, Berlin, Germany \\ ${ }^{f}$ Max-Planck-Institut für Meteorologie, Hamburg, Germany \\ IInstituto Nazionale di Geofisica e Vulcanologia, Bologna, Italy \\ ${ }^{h}$ NCAR, Boulder, Colorado \\ ${ }^{i} G F D L$, Princeton, New Jersey \\ ${ }^{j}$ University of Hawaii at Manoa, Honolulu, Hawai \\ ${ }^{k}$ York University, Toronto, Ontario, Canada \\ 'Met Office, Bracknell, Berkshire, United Kingdom
}

(Manuscript received 30 August 2002, in final form 28 May 2003)

\begin{abstract}
It is recognized that the resolved tropical wave spectrum can vary considerably among general circulation models (GCMs) and that these differences can have an important impact on the simulated climate. A comprehensive comparison of low-latitude waves is presented for the December-January-February period using highfrequency data from nine GCMs participating in the GCM Reality Intercomparison Project for Stratospheric Processes and Their Role in Climate (GRIPS; SPARC). Quantitative measures of the wavenumber-frequency structure of resolved waves and their impacts on the zonal mean circulation are given. Space-time spectral analysis reveals that the wave spectrum throughout the middle atmosphere is linked to the variability of convective precipitation, which is determined by the parameterized convection. The variability of the precipitation spectrum differs by more than an order of magnitude among the models, with additional changes in the spectral distribution (especially the frequency). These differences can be explained primarily by the choice of different cumulus parameterizations: quasi-equilibrium mass-flux schemes tend to produce small variability, while the moistconvective adjustment scheme is the most active. Comparison with observational estimates of precipitation variability suggests that the model values are scattered around the observational estimates. Among the models, only those that produce the largest precipitation variability can reproduce the equatorial quasi-biennial oscillation (QBO). This implies that in the real atmosphere, the forcing from the waves, which are resolvable with the typical resolutions of present-day GCMs, is insufficient to drive the QBO. Parameterized cumulus convection also impacts the nonmigrating tides in the equatorial region. In most of the models, momentum transport by diurnal nonmigrating tides in the mesosphere is comparable to or larger than that by planetary-scale Kelvin waves, being more significant than has been thought. It is shown that the westerly accelerations in the equatorial semi-annual oscillation in the models examined are driven mainly by gravity waves with periods shorter than 3 days, with some contribution from parameterized gravity waves, and that the contribution from the wavenumber1 Kelvin waves is negligible. These results provide a state-of-the-art assessment of the links between convective parameterizations and middle-atmospheric waves in present-day middle-atmosphere climate models.
\end{abstract}

\section{Introduction}

Vertically propagating waves from the troposphere play important roles in the equatorial middle atmosphere. The horizontal momentum they carry is deposited as they are damped in the middle atmosphere, pro-

Corresponding author address: Takeshi Horinouchi, Radio Science Center for Space and Atmosphere, Kyoto University, Uji 611-0011, Japan.

E-mail: horinout@ kurasc.kyoto-u.ac.jp viding the forcing of the low-frequency oscillations: the quasi-biennial oscillation (QBO) in the lower and middle stratosphere (e.g., Baldwin et al. 2000), and the semiannual oscillation (SAO) in the upper stratosphere and mesosphere (e.g., Holton 1975; Holton and Wehrbein 1980). As discussed below, many studies have isolated waves in the equatorial middle atmosphere of general circulation models (GCMs) and shown that these waves play a role in forcing the simulated climates. However, the temporal and spatial structure of these waves can differ among models. While this point is 
important when interpreting GCM simulations, the differences among present-day models have not been characterized in any detail. To investigate them requires a careful comparison of high-frequency output from many models. Here we present the results of such a study.

The waves observed in the equatorial middle atmosphere have a wide variety of horizontal scales (see Baldwin et al. 2000 for review). These range from planetary-scale Kelvin waves and synoptic-scale mixed Rossby-gravity waves, down to mesoscale gravity waves with spatial scales of $O(1000)$ to $O(10) \mathrm{km}$. It is now widely supposed that most of these waves are excited in the troposphere, mainly through cumulus convection. Even though each convective tower has a horizontal scale of $O(1)$ to $O(10) \mathrm{km}$, cumulus convection can excite a broad spectrum of waves, because of its organization over various horizontal distances, ranging from the mesoscale to the planetary scale.

There are currently insufficient observations to determine the horizontal wavelengths that dominate the forcing of he QBO and SAO. The early model of Holton and Lindzen (1972) supposed that the QBO was driven mainly by planetary-scale Kelvin waves and Rossbygravity waves, but it is now believed that a significant portion of the forcing is due to gravity waves with wavelengths on the order of a thousand kilometres (Dunkerton 1997). However, it is still an open question whether even smaller-scale gravity waves play a key role in the forcing of the QBO; if this is the case, a significant portion of the QBO forcing must come from gravity waves of subgrid-scale in the typical resolutions of GCMs used for multiyear simulations of the middleatmosphere climate system. The situation is quite similar for the SAO. At first, planetary-scale Kelvin waves were supposed to drive the westerly phase of the SAO (Holton 1975), but their forcing was reported to be insufficient (Hitchman and Leovy 1988). Furthermore, Ray et al. (1998) suggested that the westerly forcing by waves with wavelength down to a few thousand kilometers is not sufficient. The relative contribution of various scales of waves to the forcing of the SAO is still an open question.

Since the QBO impacts the entire middle atmosphere and dominates tropical variability, its representation is an important requirement in climate models. However, the QBO has been simulated in only a few GCMs, and the roles of resolved and parameterized waves remain unclear. In some simulations, the QBO was forced solely by resolved waves (Takahashi 1996, 1999; Horinouchi and Yoden 1998, hereafter HY98; Hamilton et al. 2001), while in others parameterized gravity waves account for a substantial part of the QBO forcing (Scaife et al. 2000; Giorgetta et al. 2002). In contrast, most GCMs with adequate vertical extent do simulate an SAO signal. This is because the easterly phase of the SAO is largely driven by interhemispheric transport of angular momentum during the solsticial seasons (Holton and Wehrbein 1980). Simulated SAOs differ significantly among
GCMs and are often not realistic (e.g., Amodei et al. 2001). An exception is the model described by Medvedev and Klaassen (2001), which does produce a rather realistic SAO.

In GCMs, diabatic heating and cooling due to cumulus parameterization are the dominant source of resolved waves in the equatorial region. The simulations mentioned above in which the QBO is driven solely by resolved waves used the moist convective adjustment scheme to represent the effects of cumulus convection. Recently, Ricciardulli and Garcia (2000) examined the variability of diabatic heating due to parameterized cumulus convection in the National Center for Atmospheric Research (NCAR) Community Climate Model 3 (CCM3). They showed that the variability produced by the standard convective parameterization of the model, the Zhang and McFarlane (1995) scheme, is much smaller than that obtained by HY98, who used the moist convective adjustment scheme. Accordingly, the momentum flux inferred from convection is smaller with the standard scheme.

The diurnal cycle of tropospheric latent heating due to cumulus convection excites atmospheric tides (Lindzen 1978; Hamilton 1981). Although radiative heating is the dominant source of migrating tides, latent heating contributes significantly to the excitation of nonmigrating tides (Tokioka and Yagai 1987; Williams and Avery 1996; Hagan et al. 1997). Idealized and general circulation models have been used to study the impacts of the tides on the zonal momentum budget, and it has been shown that they are important in the lower thermosphere (e.g., Miyahara et al. 1993), and that they may play some role in the upper mesosphere.

The present study examines convectively forced waves in middle-atmospheric GCMs. A number of such models have been used to study the middle-atmospheric processes and climate. Complete evaluation of our ability to simulate the atmosphere requires comprehensive comparison of various aspects of the GCMs. For this purpose, the project Stratospheric Processes and Their Role in Climate (SPARC) initiated an initiative GCM Reality Intercomparison Project for SPARC (GRIPS; Pawson et al. 2000). The present study was conducted within GRIPS, and its purpose is to investigate resolved waves in the equatorial region of various GCMs. The following specific issues are investigated.

- How can the various kinds of resolved waves in the equatorial middle atmosphere of currently used GCMs be quantified?

- How and to what extent do the waves differ among the GCMs?

- How do the results compare with observations?

- How can the difference be explained in terms of the choice of model components and their settings?

- How does the difference affect simulated mean flow?

The present study will be useful to study subgridscale gravity wave parameterizations, since parameter- 
TABLE 1. Models used in the study.

\begin{tabular}{|c|c|c|c|}
\hline Model & Acronym & Group & Reference \\
\hline MRI/JMA98 & MRI & $\begin{array}{l}\text { Meteorological Research Institute } \\
\text { and Japan Meteorological Agen- } \\
\text { cy, Japan }\end{array}$ & Shibata et al. (1999) \\
\hline FUB & FUB & Freie Universität Berlin, Germany & $\begin{array}{l}\text { Pawson et al. (1998); Langematz } \\
\text { (2000) }\end{array}$ \\
\hline MA-ECHAM4 & ECHAM & $\begin{array}{l}\text { Max-Planck-Institut, Hamburg, Ger- } \\
\text { many }\end{array}$ & Manzini et al. (1997) \\
\hline UKMO & UKMO & $\begin{array}{l}\text { Met Office, Bracknell, United } \\
\text { Kingdom }\end{array}$ & Cullen (1993); Scaife et al. (2000) \\
\hline MA-CCM3 & MACCM & NCAR, Boulder, CO & $\begin{array}{l}\text { Kiehl et al. (1998); Williamson and } \\
\text { Olson (1994) }\end{array}$ \\
\hline CMAM & CMAM & Canada & Beagley et al. (1997) \\
\hline FV-CCM3 & FVCCM & $\begin{array}{l}\text { NCAR and National Aeronautic } \\
\text { and Space Administration } \\
\text { (NASA) Goddard Space Flight } \\
\text { Center (GSFC), Greenbelt, MD }\end{array}$ & Kiehl et al. (1998); Lin (1997) \\
\hline SKYHI (N30L40) & SKYHI-LR & $\begin{array}{l}\text { Geophysical Fluid Dynamics Labo- } \\
\text { ratory (GFDL), Princeton, NJ }\end{array}$ & Hamilton et al. (1995) \\
\hline SKYHI (N45L80) & SKYHI-HR & GFDL, Princeton, NJ & Hamilton et al. (2001) \\
\hline AGCM5-HY98 & AGCM & GFD Dennou Club, Japan & HY98 (experimental aquaplanet) \\
\hline
\end{tabular}

ized waves work together with resolved waves. This study will also be useful to improve convective parameterizations, since a good deal of investigation is made regarding their characteristics to excite waves, which is found to be important for the climate modeling.

The rest of the paper is organized as follows. The models used are summarized in section 2. Results are shown in section 3 , and conclusions are drawn in section 4. The spectral method used in the study is described in appendix A, and a discussion on cumulus parameterizations in terms of wave excitation is made in appendix B.

\section{Models}

The GCMs used in this study are listed in Table 1. They will be referred to by the acronyms in the table. Several of these have been further developed since the initial GRIPS comparison of the mean states (Pawson et al. 2000). Data collection for this study began in 1998, so the most recent versions of all models are not used, but this does not impact the conclusions of the work. Unlike other models, the atmospheric general circula- tion model 5 (AGCM) was run with an experimental aquaplanet setting (HY98).

Table 2 shows specification of the model grids. Many of them are spectral with triangular truncation, typically with the T42 resolution. The Middle Atmosphere Community Climate Model (MACCM) uses a semi-Lagrangian dynamical core based on the spectral grid (Williamson and Olson 1994), and the Finite Volume Community Climate Model (FVCCM) uses a dynamical core based on the finite-volume method (Lin and Rood 1997; Lin 1997). The Met Office model (UKMO) and SKYHI use gridpoint methods. Both in terms of horizontal and vertical resolutions, the coarsest among the models is the Freie Universität Berlin model (FUB), and the finest is SKYHI-HR.

Table 3 briefly summarizes physical parameterizations in the models and some other information. Of particular interest among many kinds of parameterizations is the cumulus parameterization. The AGCM and SKYHI models use the moist convective adjustment (MCA) scheme (Manabe et al. 1965); the MRI model has the Arakawa-Schubert scheme (Arakawa and Schubert 1974) with a prognostic closure (see Shibata et al.

TABLE 2. Summary of grid specification of the models. Here, T21, for example, represents the triangular truncation at wavenumber 21.

\begin{tabular}{|c|c|c|c|c|c|}
\hline Model & Formulation & $\begin{array}{l}\text { Horizontal } \\
\text { resolution }\end{array}$ & $\begin{array}{l}\text { No. of } \\
\text { levels }\end{array}$ & $\begin{array}{l}\text { Top } \\
(\mathrm{hPa})\end{array}$ & $\begin{array}{c}\Delta z(\mathrm{~km}) \text { in } \\
\text { lower stratosphere }\end{array}$ \\
\hline MRI & Spectral & $\mathrm{T} 42$ & 45 & 0.01 & 2 \\
\hline FUB & Spectral & $\mathrm{T} 21$ & 34 & 0.01 & $2-3$ \\
\hline ECHAM & Spectral & $\mathrm{T} 42$ & 39 & 0.01 & $1.7-2.3$ \\
\hline UKMO & Grid & $3.75^{\circ} \times 2.5^{\circ}$ & 55 & 0.01 & 1.3 \\
\hline MACCM & Semi-Lagrangian & $\mathrm{T} 42$ & 54 & 0.01 & $1.1-1.5$ \\
\hline CMAM & Spectral & T32 & 50 & 0.001 & $1.7-2.3$ \\
\hline FVCCM & Finite volume & $2.5^{\circ} \times 2^{\circ}$ & 54 & 0.01 & $1.1-1.5$ \\
\hline SKYHI-LR & Grid & $3.6^{\circ} \times 3^{\circ}$ & 40 & 0.01 & $1.6-2$ \\
\hline SKYHI-HR & Grid & $2.4^{\circ} \times 2^{\circ}$ & 80 & 0.01 & $0.8-1$ \\
\hline $\mathrm{AGCM}$ & Spectral & $\mathrm{T} 42$ & 40 & 1 & 0.7 \\
\hline
\end{tabular}


TABLE 3. Summary of physical specification and miscellaneous aspects of the models. See Table B1 for more on cumulus parameterization.

\begin{tabular}{|c|c|c|c|c|c|}
\hline Model & $\begin{array}{c}\text { Cumulus } \\
\text { parameterization }\end{array}$ & $\begin{array}{l}\text { Gravity wave } \\
\text { parameterization }\end{array}$ & $\begin{array}{l}\text { Seasonal and } \\
\text { diurnal cycles }\end{array}$ & $\begin{array}{l}\text { Output } \\
\Delta t(\mathrm{~h})\end{array}$ & $\begin{array}{l}\text { Has } \\
\text { QBO? }\end{array}$ \\
\hline MRI & $\begin{array}{l}\text { Prognostic Arakawa- } \\
\text { Schubert }\end{array}$ & Orographic & Yes and yes & 3 & No \\
\hline FUB & Kuo & None & Yes and yes & 3 & No \\
\hline ECHAM & Tiedtke/Nordeng & $\begin{array}{l}\text { Orographic and nonoro- } \\
\text { graphic }\end{array}$ & Yes and yes & 3 & No \\
\hline UKMO & Gregory & $\begin{array}{l}\text { Orographic and nonoro- } \\
\text { graphic }\end{array}$ & Yes and yes & 3 & Yes \\
\hline MACCM & $\mathrm{ZM}$ & $\begin{array}{l}\text { Orographic and nonoro- } \\
\text { graphic }\end{array}$ & Yes and yes & 6 & No \\
\hline CMAM & $\mathrm{ZM}$ & Orographic & Yes and yes & 3 & No \\
\hline FVCCM & $\mathrm{ZM}$ & Orographic & Yes and yes & 3 & No \\
\hline SKYHI-LR & MCA & None & Yes and no & 3 & No \\
\hline SKYHI-HR & MCA & None & Yes and no & 3 & Yes \\
\hline AGCM & MCA & None & No and no & 3 & Yes \\
\hline
\end{tabular}

1999 for details); FUB has the Kuo (1974) scheme modified by Tiedtke et al. (1988); ECHAM has the Tiedtke (1989) scheme modified by Nordeng (1994); UKMO has the Gregory and Rowntree (1990) scheme (hereafter Gregory scheme); and MACCM, FVCCM, and the Canadian Middle Atmosphere model (CMAM) use the Zhang and McFarlane (1995) scheme (ZM). More details on the cumulus parameterizations in the models are presented in appendix B.

With regard to the parameterization of unresolved gravity waves in the models, there are three cases: with no parameterization, with the parameterization of orographic gravity waves, and with the parameterizations of orographic and nonorographic gravity waves. Since orographic waves have stationary phase speeds, they do not force equatorial mean-flow oscillations. It is only the parameterization of nonorographic waves that is relevant here. All the models except for SKYHI and AGCM have the diurnal cycle in solar insolation, and all but AGCM have climatological annual cycles in sea surface temperature. Sea surface temperature is not unified among models.

For the GCMs, data between $30^{\circ} \mathrm{S}$ and $30^{\circ} \mathrm{N}$ were saved every $3 \mathrm{~h}$ for a 3 -month period of December, January, and February (Table 3). For AGCM, an arbitrary 60-day period was chosen. The physical quantities collected were zonal and meridional winds, vertical pressure velocity $(D p / D t)$, temperature, and total (convective and large-scale) precipitation rate at the surface. The rainfall rate was averaged over the 3-h (or $6 \mathrm{~h}$ for MACCM) output time interval, while other quantities are instantaneous. At levels where the model's grid was not a pressure level, the three-dimensional output was interpolated onto constant pressure surfaces near the vertical grid points of the model. For most of the models, data above about $100 \mathrm{hPa}$ were not interpolated, since they use a pressure-hybrid coordinate. The exceptions are MRI for which interpolation is made onto the standard levels and AGCM, which uses the sigma coordinate.

\section{Results}

\section{a. Mean state}

Three of the models (UKMO, SKYHI-HR, and AGCM) have spontaneous QBO-like oscillations in the lower stratosphere, as described in the references in Table 1. While those in SKYHI-HR and AGCM are driven by resolved waves, that in UKMO is driven by both parameterized and resolved waves, with a larger contribution from the former (Scaife et al. 2000). In the other models, weak easterly zonal-mean winds dominate the lower stratosphere in the simulations. Unlike SKYHI-HR, SKYHI-LR does not have a QBO, since the vertical resolution is too low (Hamilton et al. 2001).

All models except AGCM have SAOs in the upper stratosphere and mesosphere. Time-height sections of the zonal mean zonal wind near the equator is shown in Fig. 1 for three of the models (MRI, MACCM, and SKYHI-LR). For other models, only the mean zonal wind of January is shown on the lower right. The MRI model has the weakest SAO. The SAO in MACCM propagates downward too uniformly (later we will show that it is driven predominantly by parameterized gravity waves). The SKYHI-LR model (lower left) reproduces the observed lower-mesospheric amplitude minimum of the SAO. Generally speaking, however, one cannot expect to see this separation in GCMs with tops at around $0.01 \mathrm{hPa}$ (below the mesopause). Interestingly, the SAO in SKYHI-HR (not shown) is less realistic than that in SKYHI-LR and does not have the separation (see Hamilton et al. 2001). This might be because the QBO-like oscillation in the lower stratosphere of SKYHI-HR changes the gravity waves filtered there. In this way, the modeling of the SAO cannot be separated from that of the QBO.

Figure 2 shows the horizontal distribution of precipitation between $30^{\circ} \mathrm{N}$ and $30^{\circ} \mathrm{S}$ averaged over the December, January, and February (DJF) period. Also shown is a 13-yr climatology from the Global Precipitation Climatology Project combined satellite-gauge 


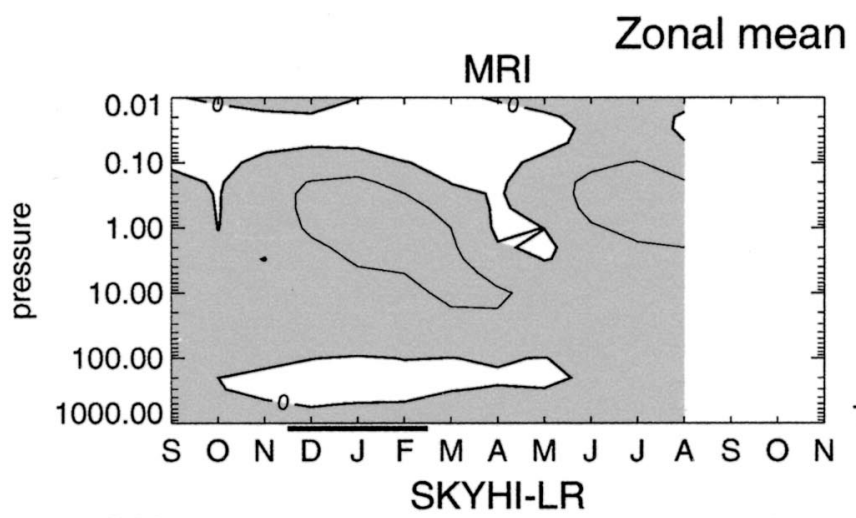

\section{Zonal mean $\mathrm{U}$ avg:10N-10S}
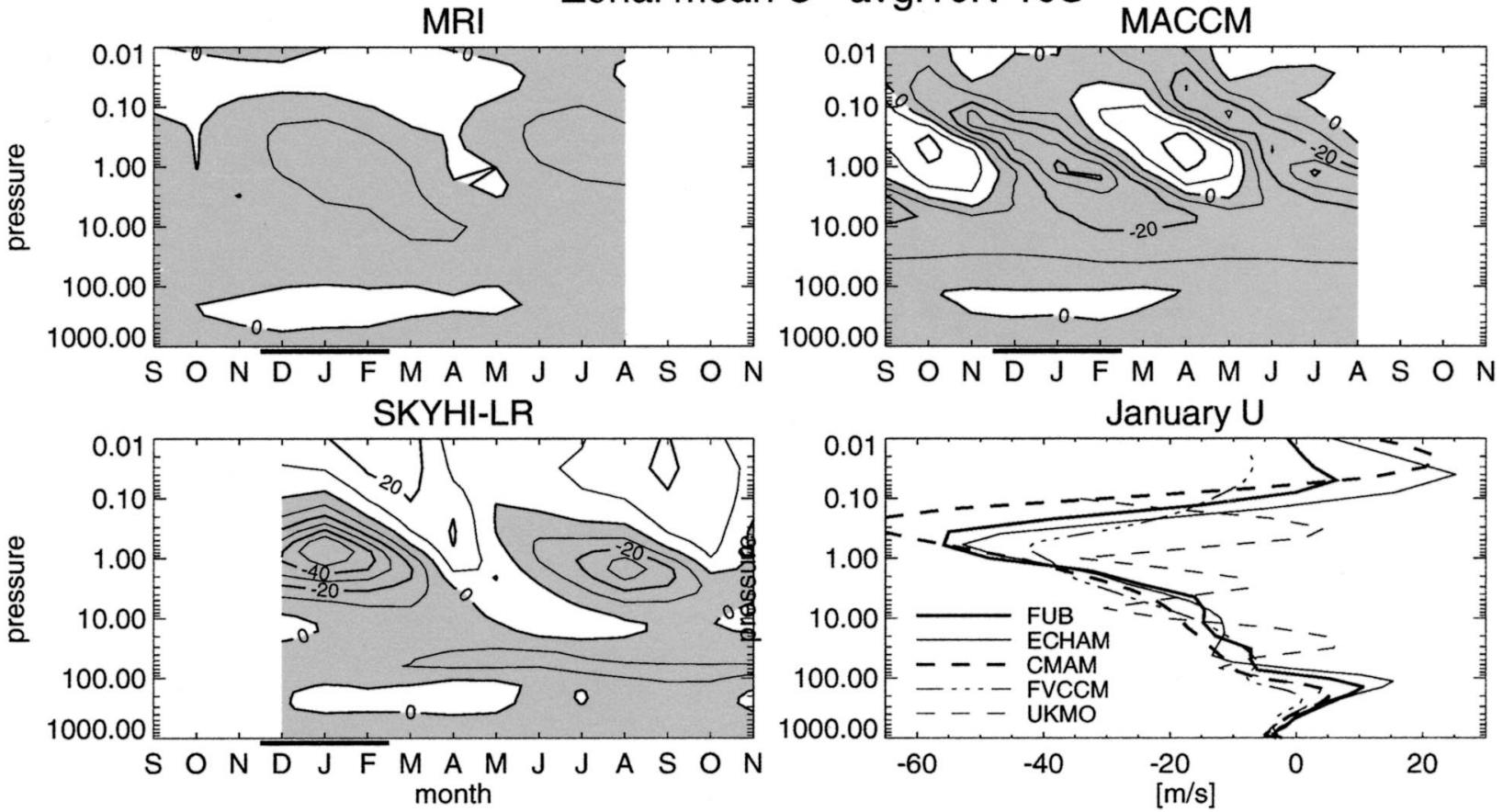

FIG. 1. Time-height section of zonal and monthly mean zonal wind averaged between $10^{\circ} \mathrm{N}$ and $10^{\circ} \mathrm{S}$ for selected models (MRI, MACCM, and SKYHI-LR) and (lower right) its height profile for Jan for other models.

precipitation estimate (Huffman et al. 1997). Figure 3 shows their zonal averages. The realism of the mean precipitation varies widely among models. For instance, its distribution in some models is biased heavily toward the equator (see Numaguti 1993 for its explanation in terms of the cumulus parameterization).

\section{b. Wavenumber-frequency spectra}

In order to investigate the sensitivity of resolved waves to parameterized cumulus convection, two-dimensional, zonal wavenumber-frequency spectra were calculated from modeled precipitation and dynamical quantities. See appendix A for the definition of spectra. Here, precipitation is used to represent vertically integrated diabatic heating due to cumulus convection in GCMs. To a first approximation, it is a good indicator of the thermal forcing of vertically propagating waves.

The left panels in Fig. 4 show the results for precipitation between $10^{\circ} \mathrm{N}$ and $10^{\circ} \mathrm{S}$. Here, frequency $\omega$ is positive definite, and zonal wavenumber $s$ is positive (negative) for eastward-propagating (westward propagating) disturbances. The two-dimensional precipitation spectra are compressed into one-dimensional frequency spectra in Fig. 5a by integrating with respect to wavenumber. We now examine the spectra in light of the cumulus schemes. See appendix B for a further discussion.

The overall power of the precipitation in the models with the MCA scheme (SKYHI, AGCM) is significantly larger than that with any other cumulus parameterization (Figs. 4 and 5a). Broad peaks are found between 0.2 and 0.5 cycles per day (cpd) with respect to frequency, while the power is largest around the highest wavenumbers (Fig. 4). Note that these models were run without the diurnal cycle of solar insolation. The spectrum from SKYHI-HR (not shown in Fig. 4) is similar to SKYHI$\mathrm{LR}$, but the total power is larger than the latter because of the contribution of the wavenumbers that is not resolved in SKYHI-LR (Fig. 5a).

The overall power with the ZM scheme (MACCM, CMAM, FVCCM) is the smallest. The UKMO model (with the Gregory scheme) also produces as small power as the ZM scheme except at high frequencies. In these four models, the spectra have sharp peaks at the diurnal frequency and its higher harmonics. Diurnal variations of convection occur predominantly over continents. The continuous part of the spectra aside the diurnal frequency and its harmonics show maxima roughly around $0.1 \mathrm{cpd}$ (Fig. 4). Westward-moving components are slightly stronger than eastward-moving components.

The overall power of precipitation with the prognostic Arakawa-Schubert scheme (MRI), Kuo scheme (FUB), and Tiedtke/Nordeng scheme (ECHAM) are in between the maximum (with the MCA scheme) and minimum (ZM and Gregory schemes) cases mentioned above. The continuous part of the precipitation spectra in MRI has a peak near $1 \mathrm{cpd}$, while it is at around $0.2 \mathrm{cpd}$ in FUB. Among these three models, the overall power in ECHAM is largest. Interestingly, the spectral shape 

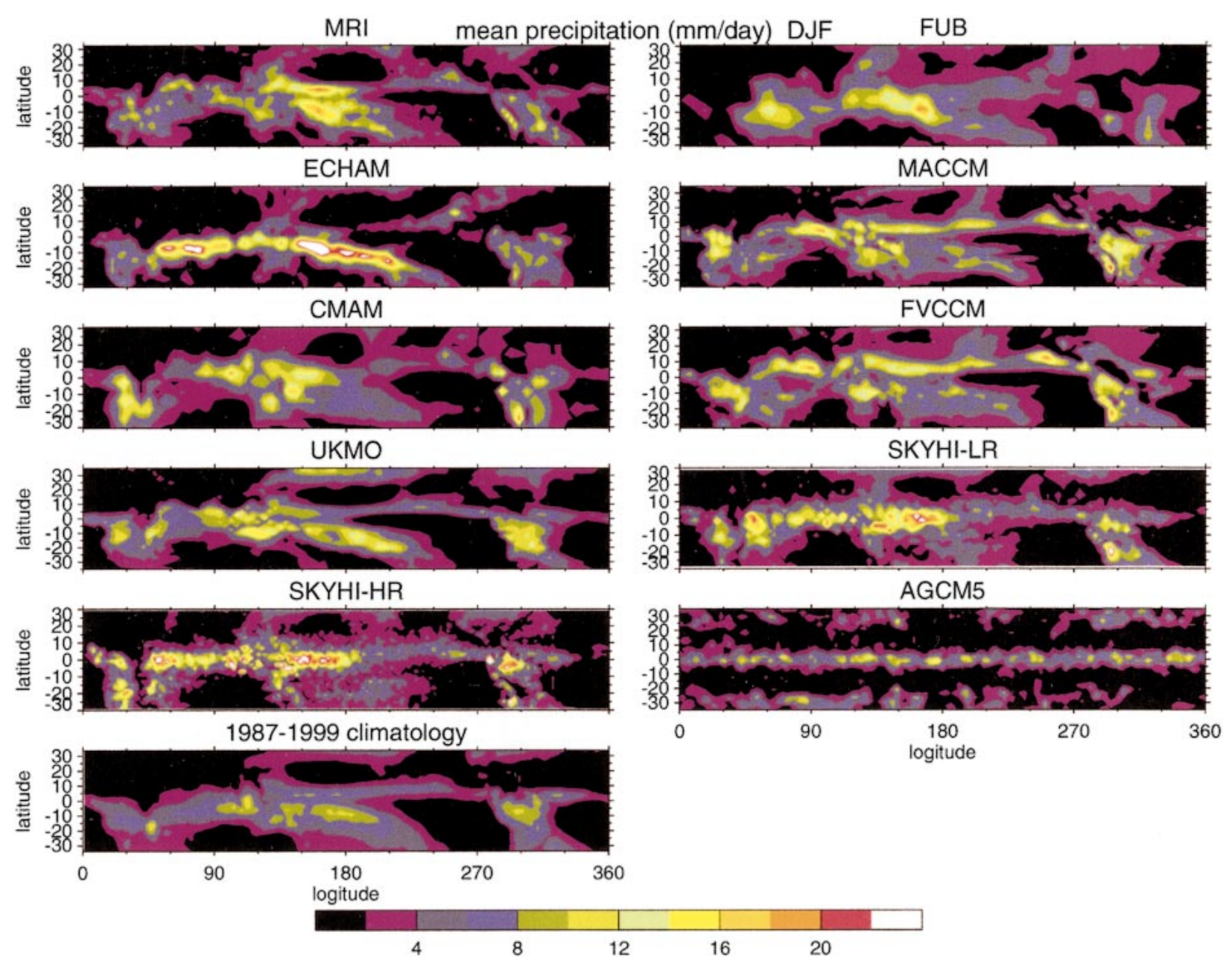

FIG. 2. Mean precipitation (mm day ${ }^{-1}$ ) for each model over the DJF period (or over a 60-day period for AGCM). (bottom) Climatology data from the Global Precipitation Climatology Project over 1987-99 for DJF.

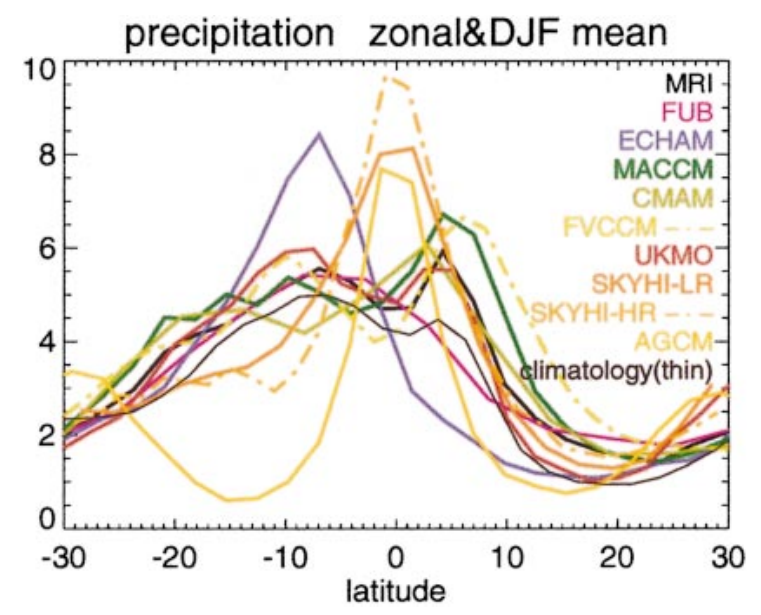

FIG. 3. As in Fig. 2, but for zonal mean. looks like that which would be obtained by adding the powers in MRI and FUB.

The large overall difference in the spectra among the models indicates that the variance of precipitation, which is obtained by integrating the spectra, differs by more than one order of magnitude. This difference is, of course, much larger than that in mean tropical precipitation among the models. This indicates that the difference in variance is primarily due to the difference in intermittency; the variance with respect to time is small (large) if precipitation is continuous (intermittent) when the time-averaged precipitation is about the same [see Horinouchi (2002, hereafter H2002) for more detailed discussion on this issue]. Therefore, the small variance with the ZM scheme, for example, arises because the modeled precipitation is less variable with time than that with the MCA scheme.

In Fig. 4 (middle and right panels) the zonal wavenumber-frequency distribution is shown of the vertical component of the Eliassen-Palm (EP) flux averaged between $10^{\circ} \mathrm{N}$ and $10^{\circ} \mathrm{S}$. Its vertical component and its 

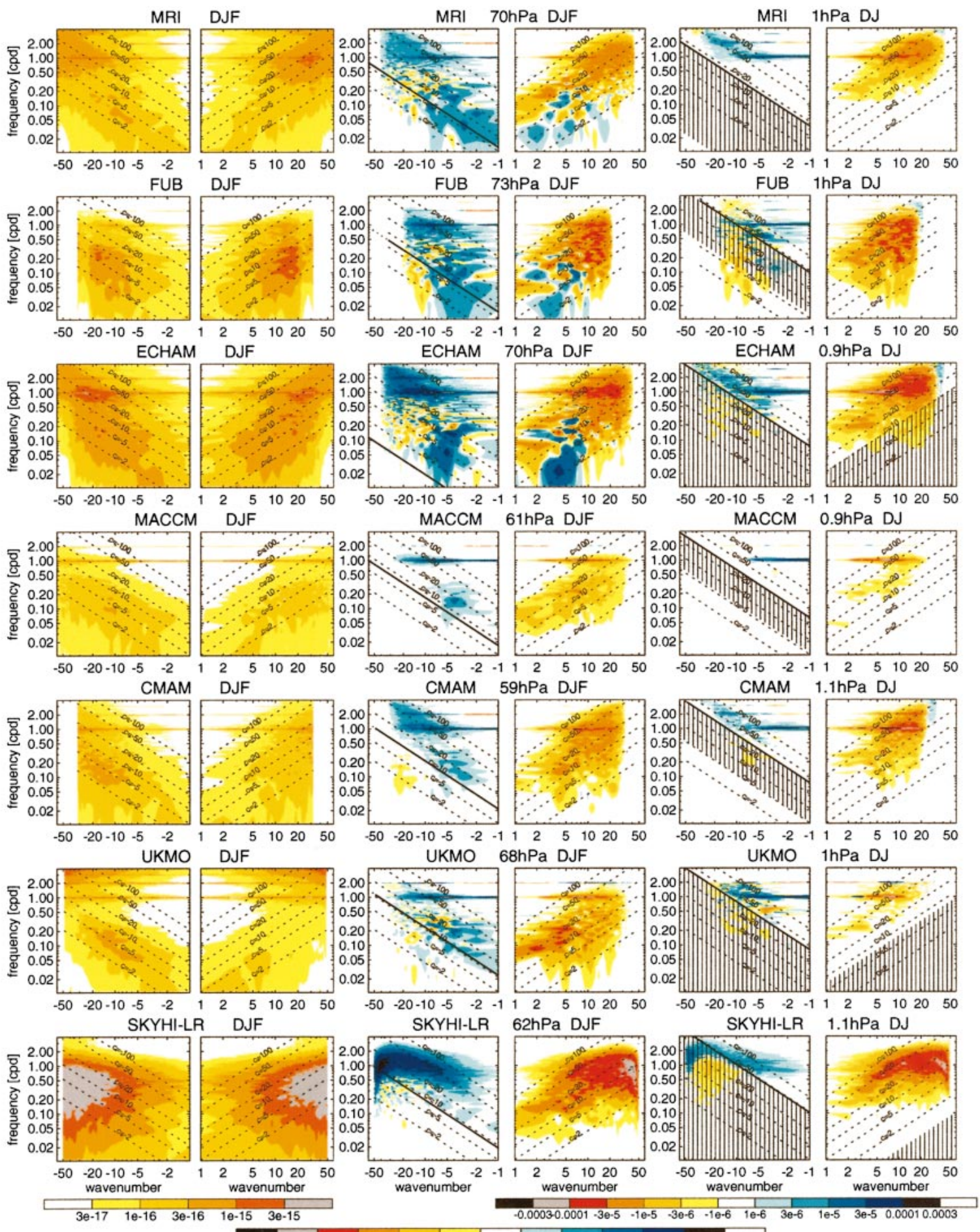

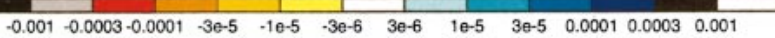

Fig. 4. (left) Two-dimensional, zonal wavenumber-frequency spectra of precipitation rate $\left(\mathrm{m}^{2} \mathrm{~s}^{-2}=1.34 \times 10^{-16} \mathrm{~mm}^{2}\right.$ day-2); (middle) $\tilde{F}^{(z)}$ at levels near $65 \mathrm{hPa}(\mathrm{Pa})$; (right) $\tilde{F}^{(z)}(\mathrm{Pa})$ at levels near $1 \mathrm{hPa}$. Seven models were selected for conciseness. The spectra were calculated at each latitude, averaged afterward between $10^{\circ} \mathrm{S}$ and $10^{\circ} \mathrm{N}$, and plotted in the energy-content form after smoothing (see appendix A). Calculations are made from the data over the DJF period for the left and middle panels, but only the data over Dec and Jan are used for the right panels (because the mean wind changes fast at the stratopause level due to the SAO). Color levels are set logarithmically. Dotted lines show zonal phase velocities. Thick solid lines in the middle and right panels show the time-averaged zonal mean zonal wind at the levels. Shading with thin solid lines at the right panels are made between its maximum and minimum of the mean wind over the height ranges between $100 \mathrm{hPa}$ and the levels shown. 

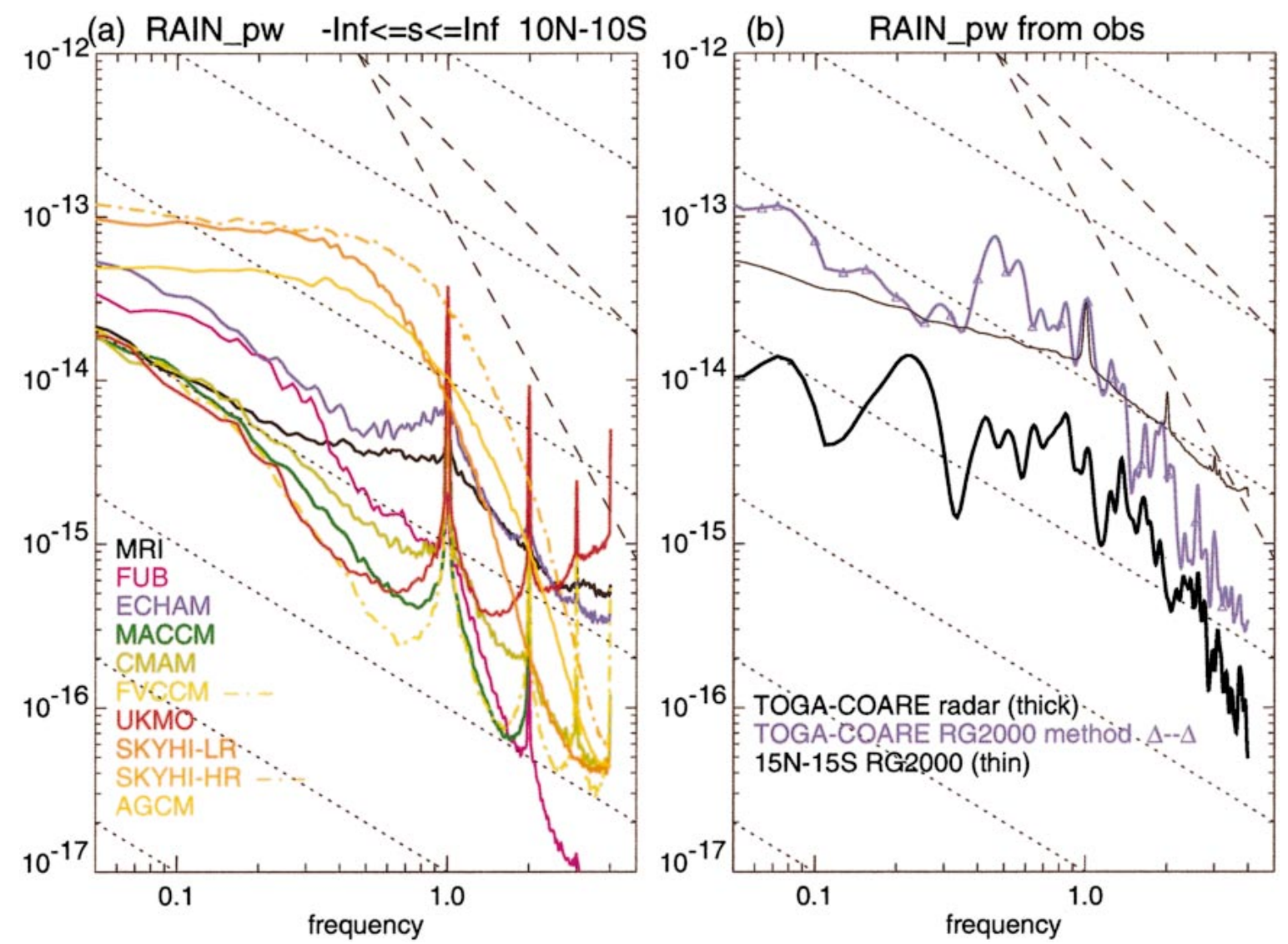

FIG. 5. (a) Frequency (cpd) spectra of precipitation ( $\mathrm{m}^{2} \mathrm{~s}^{-2}$ day; not in the energy-content form). The calculation is made for the entire 3 -month period ( 2 months for AGCM), but the spectra are shown only above $0.05 \mathrm{cpd}$. (b) Observational estimates of precipitation spectra. Dotted lines with a slope of -1 are drawn in order to facilitate to see how the spectra would look like if they were plotted in the energycontent form. Dashed lines having slopes of -3 and $-5 / 3$ are drawn just for reference.

zonal wavenumber-frequency distribution are referred to as $F^{(z)}(y, z)$ and $\tilde{F}^{(z)}(\omega, s, y, z)$, the latter being defined by Eq. (A2). Negative (positive) values indicate upward group propagation for waves that propagate eastward (westward) with respect to the mean flow, which is shown by the thick solid lines. The shaded region in each panel on the right-hand side of Fig. 4 indicates that there is a critical level between 100 and $1 \mathrm{hPa}$ for a wave whose wavenumber and frequency are in it.

Slightly above the tropopause (middle column in Fig. 4), the sign of $\tilde{F}^{(z)}$ is predominantly negative (positive) for eastward (westward) moving components, indicating the dominance of upward group propagation. Exceptionally, westward-moving semidiurnal tides with $|s|$ $\leq 3$ exhibit downward group propagation in most models, presumably because this level is below the maximum of ozone heating. Also, in some models, especially ECHAM, $\tilde{F}^{(z)}$ shows positive values for eastward-moving, synoptic-scale, and slow phase-speed (less than 20 $\mathrm{m} \mathrm{s}^{-1}$ ) components, which seems to suggest downward propagation. However, this is due to synoptic-scale Rossby waves from higher latitudes, whose group propagation is predominantly equatorward and slightly up- ward (not shown). Their apparent eastward intrinsic propagation can at least partly be explained by longitudinal variation of background zonal wind (Horinouchi et al. 2000).

As seen in Fig. 4, there are large differences in the magnitude of $\tilde{F}^{(z)}$ among the models, which clearly reflect the differences in the precipitation spectra. The main exceptions to this are the signature of Rossby waves in the lower stratosphere (middle panels) and in wavenumber-frequency ranges in which critical levels exist for the stratopause cases (shaded region in right panels). The good correspondence between the precipitation spectra and $\tilde{F}^{(z)}$ continues to higher altitudes in the mesosphere (not shown).

Since the differences of the power of precipitation are explained mainly by the cumulus parameterization methods, we can conclude that the choice of the cumulus parameterization profoundly affects the generation of vertically propagating waves in the models. Note, however, that the power of precipitation is not uniformly "projected" onto the vertically propagating waves, as shown by Salby and Garcia (1987). For example, $\tilde{F}^{(z)}$ is small for small zonal phase velocities. Also, there are 
a number of factors that affect wave propagation, but the fact that there is a clear correspondence between the precipitation spectra and $\tilde{F}^{(z)}$ throughout the middle atmosphere suggests the primary importance of convective parameterization.

\section{c. Comparison with observations}

Figure $5 \mathrm{~b}$ shows the precipitation spectra derived from observations. It shows spectra obtained by $\mathrm{H} 2002$ from two precipitation estimates during the intensive observation period of the Tropical Oceans Global Atmosphere Coupled Ocean-Atmosphere Response Experiment (TOGA COARE) conducted over the western Pacific. One of the precipitation estimates is derived from dual shipborne C-band radars, and the other is from a geostationary satellite using the same method as in Ricciardulli and Garcia (2000; hereafter RG2000) for the period and area identical to the radar data. Also shown in the figure is the precipitation spectrum derived by RG2000 as an average over the entire equatorial region between $15^{\circ} \mathrm{N}$ and $15^{\circ} \mathrm{S} .{ }^{1}$ While both $\mathrm{H} 2002$ spectra are derived from precipitation averaged over 3 $\mathrm{h}$ and a $4 \mathrm{deg}^{2}$ domain, the RG2000 spectrum is equivalent to being derived from 3-hourly precipitation averaged over $0.5 \mathrm{deg}^{2}$ grid cells covering the Tropics.

To compare the observational results with the GCM results in Fig. 5a, it may seem that RG2000's result should be used, since it covers the entire Tropics. However, the RG2000 result is a severe overestimate and cannot be used for the present purpose because of the following reasons:

- The horizontal resolution of precipitation, $0.5 \mathrm{deg}^{2}$, is much higher than the resolutions of GCMs. The finer the resolution is, the larger the power is, since the variability on smaller scales is accumulated. This effect should be severe, especially at frequencies higher than $1 \mathrm{cpd}$.

- Even if adequate resolution is used, their algorithm overestimates the power, as is evident in the difference between the two H2002 spectra for the TOGA COARE case.

For these reasons, the power of precipitation on the typical resolutions of GCMs is expected to be close to (or even smaller than) the H2002 spectrum from the TOGA COARE radar data.

Although a large uncertainty exists regarding observationally valid values, comparison with the radar-based spectrum suggests that, unlike the conclusions of RG2000, the power obtained with the MCA scheme (AGCM and SKYHI) is too large and that with the ZM (CMAM and the CCMs) or the Gregory schemes

${ }^{1}$ Since the spectrum shown in RG2000 was mistakenly multiplied by a factor of 2 (Lucrezia Ricciardulli 2002, personal communication), it is halved. Then it is multiplied by a factor to convert the units.
TABLE 4. $\left|F^{(z)}\right|$ averaged between $10^{\circ} \mathrm{N}$ and $10^{\circ} \mathrm{S}$ at a level close to $65 \mathrm{hPa}$ for various frequency ranges $\left(10^{-3} \mathrm{~Pa}\right)$. Also shown are observational estimates taken from SD97 and HV01. Note that comparison with the observational estimates is limited.

\begin{tabular}{llcl}
\hline \multicolumn{1}{c}{$\omega(\mathrm{cpd})$} & $0.33-0.97$ & $0.97-1.03$ & $1.03-3.3$ \\
\hline MRI & 0.10 & 0.038 & 0.074 \\
FUB & 0.16 & 0.026 & 0.035 \\
ECHAM & 0.20 & 0.099 & 0.22 \\
MACCM & 0.032 & 0.056 & 0.012 \\
CMAM & 0.096 & 0.070 & 0.075 \\
FVCCM & 0.0089 & 0.042 & 0.0056 \\
UKMO & 0.053 & 0.10 & 0.022 \\
SKYHI-LR & 0.64 & & 0.38 \\
SKYHI-HR & 0.52 & & 1.6 \\
AGCM & 1.1 & & 0.82 \\
SD97 & $0.7 \sim 1.3$ & & \\
SD97 $\times 0.3$ & $0.2 \sim 0.4$ & & 0.2 \\
HV01 & & & \\
\hline
\end{tabular}

(UKMO) is too small (except for sharp tidal peaks). The observational power is rather closer to that with the Tiedtke/Nordeng (ECHAM) or the prognostic ArakawaSchubert scheme (MRI). More observational studies are needed to evaluate the spectra with confidence.

The magnitude of $F^{(z)}$ at around $65 \mathrm{hPa}$ in GCMs is summarized in Table 4 by showing $\left|F^{(z)}\right| \equiv F_{w}^{(z)}-$ $F_{e}^{(z)}$, where $F_{w}^{(z)}$ and $F_{e}^{(z)}$ represent decomposition of $F^{(z)}$ onto contributions from westward- and eastward-moving disturbances, respectively. Also shown in the table are observational estimates by Sato and Dunkerton (1997, hereafter SD97) and Hertzog and Vial (2001, hereafter HV01). The SD97 result is based on multiyear operational radiosonde observation, while the HV01 result is based on data from a few balloons that floated at roughly a constant pressure of $50 \mathrm{hPa}$. Since SD97 stated that the actual value could be $30 \% \sim 70 \%$ of their estimates, we added, in Table 4, the minimum case by multiplying by a factor of 0.3 . Since HV01 obtained $\left|F^{(z)}\right|$ integrated between 1 and $24 \mathrm{cpd}$, the value in Table 4 is reduced from the original by multiplying a factor of 0.38 to convert in the integration between 1 and $3.3 \mathrm{cpd}$, the factor being derived by assuming the spectral slope of -1 they obtained. The HV01 result might be an underestimate, since their method does not rigorously separate the eastward- and westward-moving components. Also, it is derived from only a small number of data.

Although there are large uncertainties in these observational estimates, it is worth comparing the GCM results with them. The results shown in Table 4 for momentum flux are not inconsistent with what was suggested with Fig. 5 for simulated precipitation, unless the maximum value of SD97's estimates should be used. Namely, convective excitation in the models with the MCA scheme is too strong, and that in the models with the ZM and Gregory schemes is too weak. 

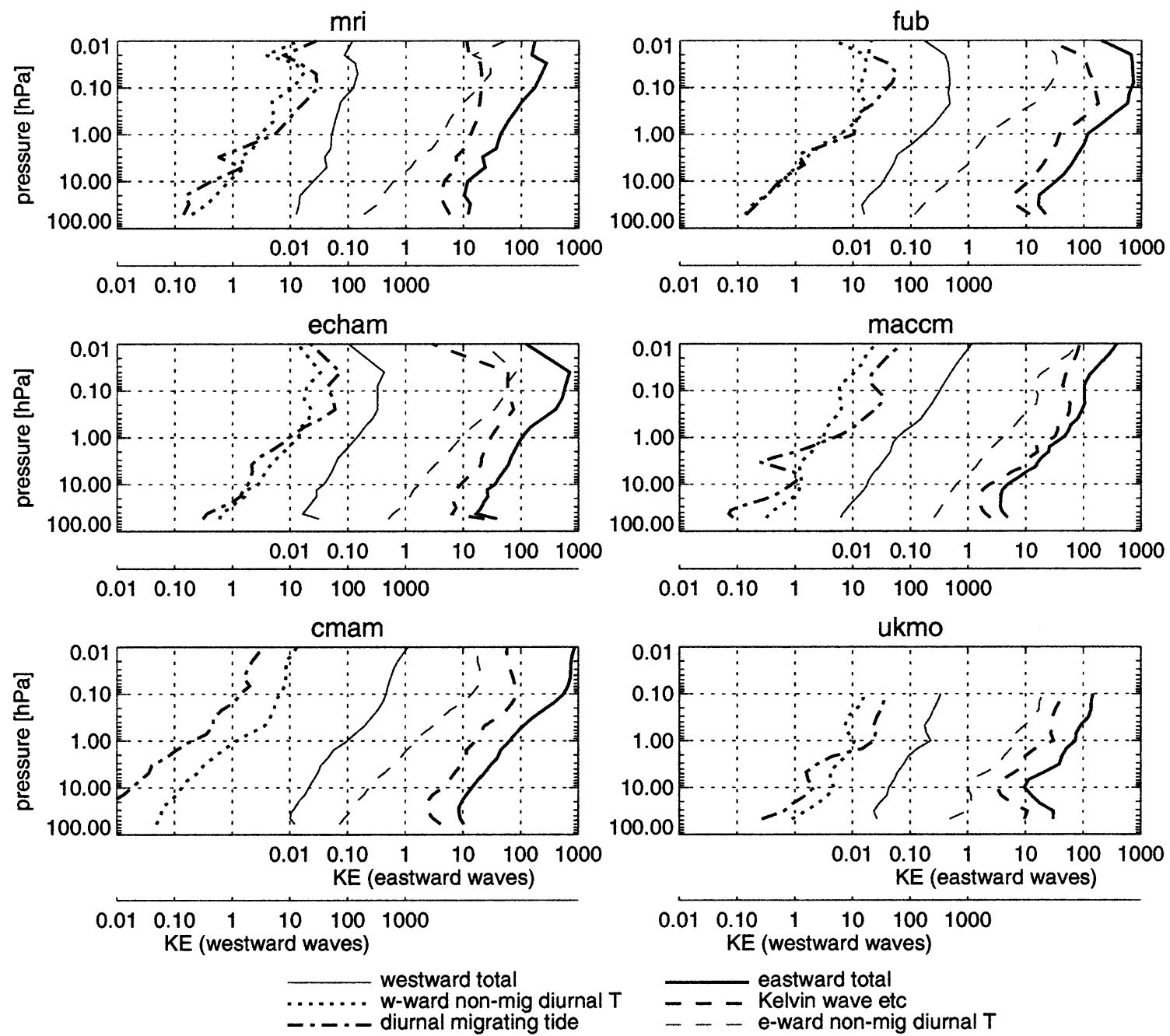

FIG. 6. Vertical distribution of kinetic energy $\left(\mathrm{m}^{2} \mathrm{~s}^{-2}\right)$ defined as $u^{2}+v^{2}$ averaged between $10^{\circ} \mathrm{N}$ and $10^{\circ} \mathrm{S}$ for disturbances classified in terms of $s$ and $\omega$ : westward-moving disturbances in total (thin solid lines), nonmigrating westward-moving diurnal tides defined by the integration over $s \leq-2$ and $0.97<\omega<1.03$ (dotted lines), migrating diurnal tides with $s=-1$ and $0.97<\omega<1.03$ (dashed-dotted lines), eastward-moving disturbances in total (thick solid lines), eastward-moving disturbances including planetary-scale Kelvin waves with $+1 \leq s \leq+3$ and $\omega<0.3 \mathrm{cpd}$ (thick-dashed lines), and eastward-moving nonmigrating diurnal tides with $s \geq+1$ and $0.97<\omega<1.03$ cpd (thin-dashed lines). Six models were selected for conciseness. The abscissae are shifted by three orders of magnitude between westwardand eastward-moving disturbances.

\section{d. Kelvin, gravity, and tidal waves}

We present in this section the relative contributions of different kinds of waves to energy and momentum flux in the simulated equatorial middle atmospheres. It is done by separating waves spectrally in the zonal wavenumber-frequency space.

\section{1) Kelvin waves}

Figure 6 shows the kinetic energy of disturbances of selected wavenumber-frequency ranges. It generally grows with altitude, since it does not contain the density factor. The energy of eastward-moving low-frequency (up to $0.3 \mathrm{cpd}$ ), low-wavenumber (1 to 3 ) disturbances, which include planetary-scale Kelvin waves, is between one-third to one-half of the total energy of eastwardmoving disturbances in the stratosphere of many models. The ratio is generally smaller in the mesosphere than in the stratosphere. The contribution of these disturbances is much smaller in $F^{(z)}$ than in the kinetic energy throughout the middle atmosphere, as shown in Fig. 7. For most altitudes, it is $10 \%$ or less in models other than MACCM and FVCCM, in which the ratio is about one-half or less. Therefore, the momentum transfer due to Kelvin waves is far from dominant in most models. The contrast between the ratio in terms of kinetic energy and $F^{(z)}$ is explained as follows: since the spectra of vertical wind, used to derive $F^{(z)}$, are shallower with respect to frequency and horizontal wave- 

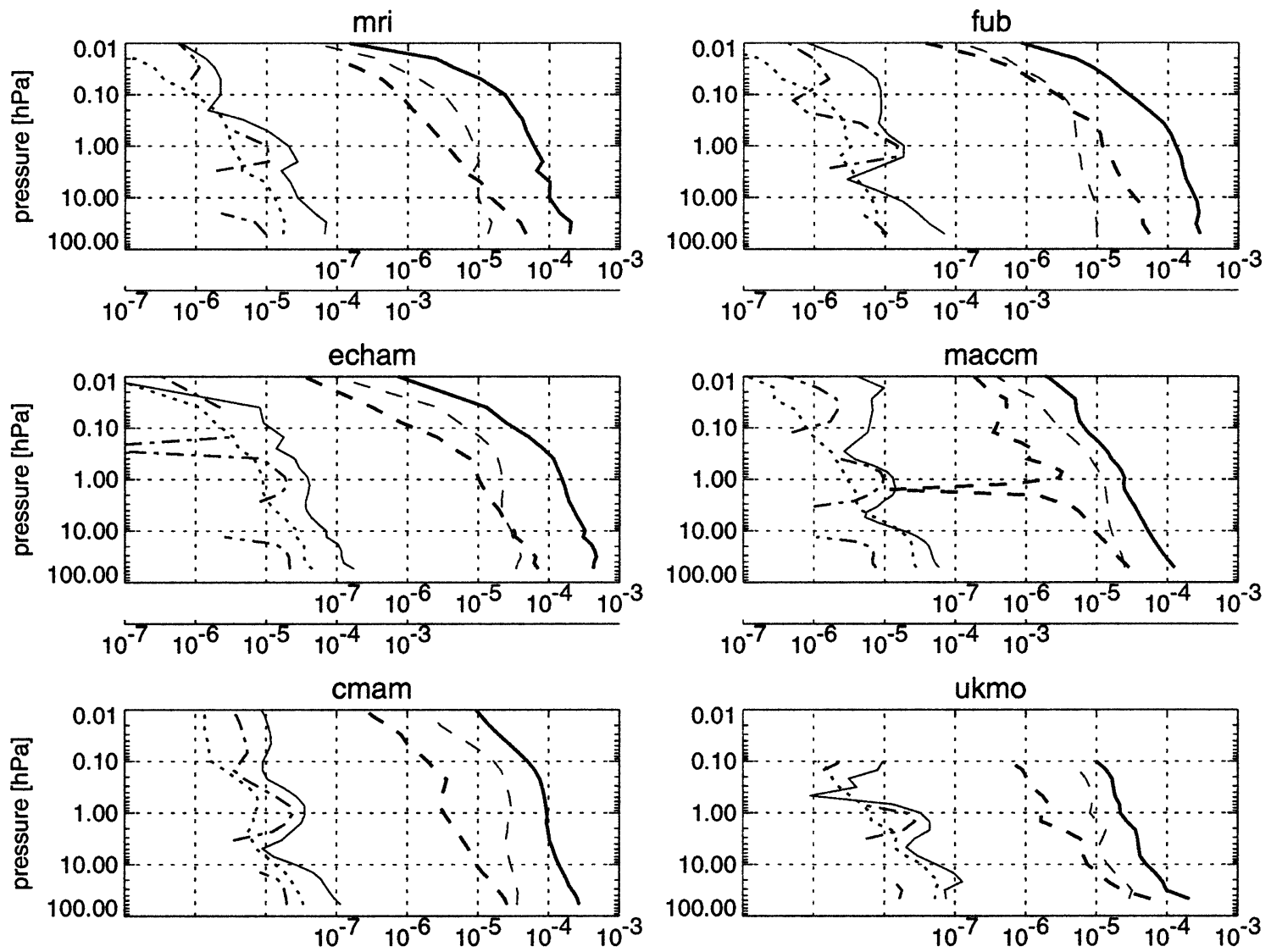

$(-1)^{\star} \mathrm{Fz}$ (eastward waves)

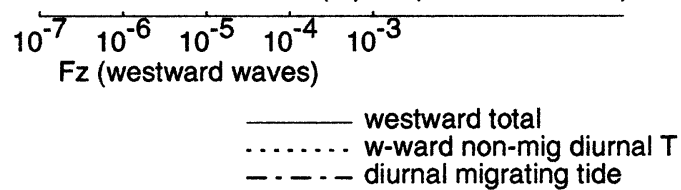

$(-1)^{\star} \mathrm{Fz}$ (eastward waves)

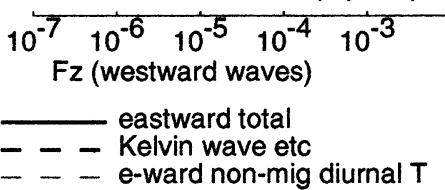

FIG. 7. As in Fig. 6, but for $F^{(z)}(\mathrm{Pa})$.

number than those of horizontal wind, the contribution of synoptic- or smaller-scale waves are more pronounced in $F^{(z)}$ than in the energy.

Figure 8 shows the wavenumber distribution of $F^{(z)}$ for various frequency ranges at around $65 \mathrm{hPa}$. The $s$ $=+1$ component in the upper-left panel includes the classical Kelvin waves with periods from 10 to 20 days observed dominantly in the lower stratosphere and the "fast" and "ultrafast" Kelvin waves that are observed in the upper stratosphere and mesosphere. From the figure, it is clear that the $s=1$ Kelvin waves carry only a very small fraction of the total momentum flux in all models in the lower stratosphere. This is also the case for the upper stratosphere and the lower mesosphere.

\section{2) TIDES}

As indicated by the two-dimensional spectra of precipitation and momentum flux (Fig. 4), there is a clear correspondence between $F^{(z)}$ due to nonmigrating di- urnal tides and the power of the diurnal component of precipitation. This result indicates that a significant fraction of the nonmigrating tides in the equatorial stratosphere, which should predominantly have the form of gravity waves, is due to convective heating, as suggested by previous studies. Figure 6 shows that in all models, the kinetic energy of eastward-moving nonmigrating tides is smaller than that of the planetary-scale disturbances including Kelvin waves in the stratosphere, which is also the case for the lower mesosphere in many models. On the other hand, as seen in Fig. 7, the momentum transport by the eastward-moving nonmigrating tides is larger than that by planetary-scale Kelvin waves above the lower stratosphere in most models.

In many models, the kinetic energy of westward-moving nonmigrating tides is comparable to or even larger than that of the migrating tides for a larger range of altitudes (Fig. 6). The energies of the $s=-2$ tide in four models (MRI, FUB, MACCM, and CMAM) are comparable with or slightly larger than that obtained by 


\section{Fz_spect $0.1 \leq \mathrm{f} \leq 0.3 \quad 10 \mathrm{~N}-10 \mathrm{~S} 65 \mathrm{hPa}$}

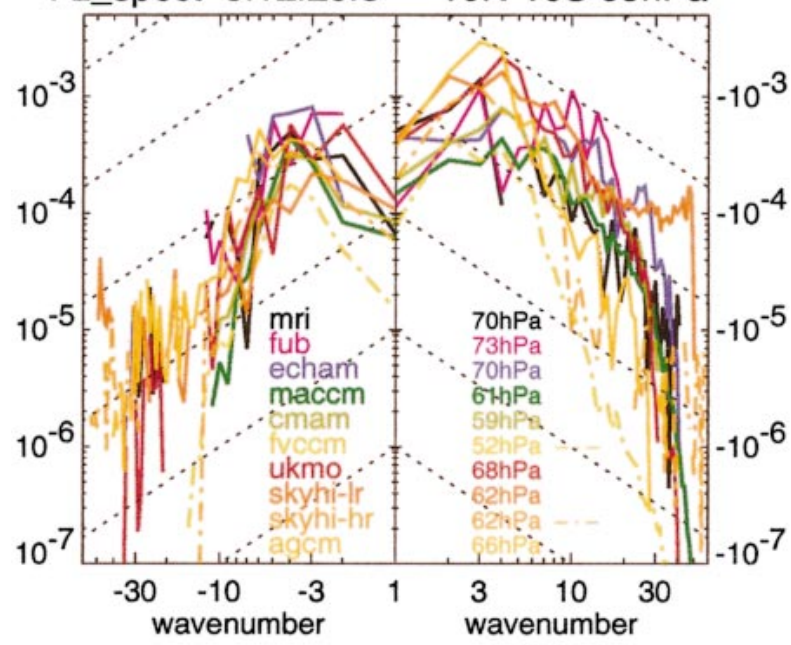

Fz_spect $0.97 \leq f \leq 1.03 \quad 10 \mathrm{~N}-10 \mathrm{~S} 65 \mathrm{hPa}$

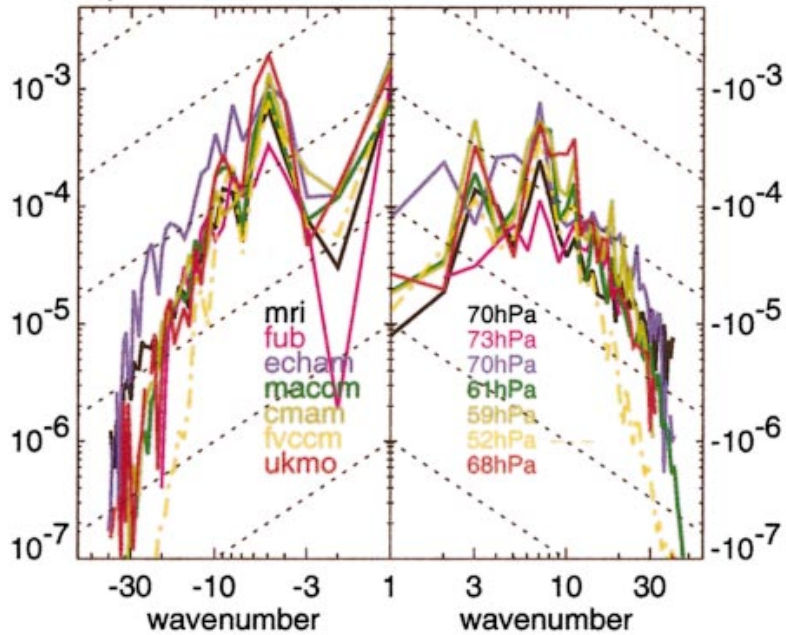

Fz spect $0.3 \leq f \leq 0.97 \quad 10 \mathrm{~N}-10 \mathrm{~S} 65 \mathrm{hPa}$

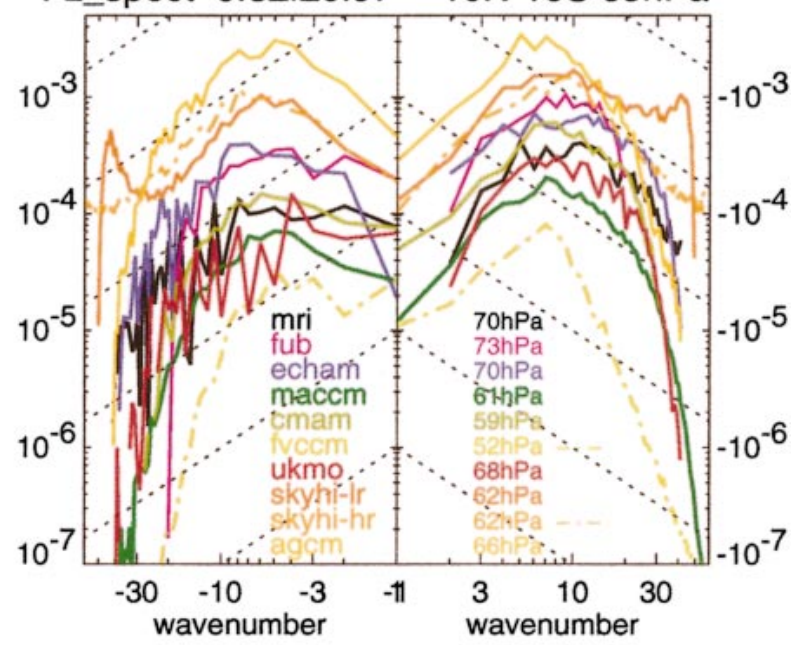

Fz_spect $1.03 \leq \mathrm{f} \leq 4 \quad 10 \mathrm{~N}-10 \mathrm{~S} 65 \mathrm{hPa}$

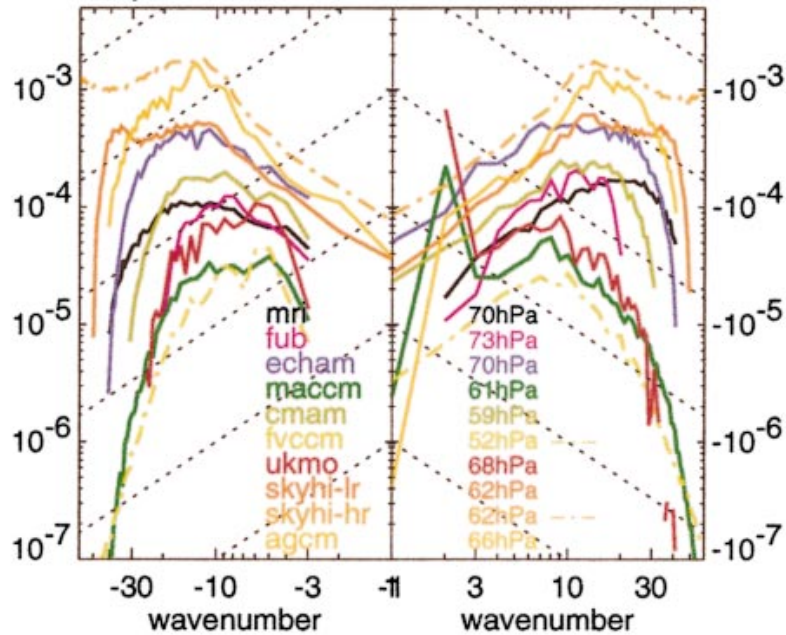

FIG. 8. Zonal wavenumber distribution of $F^{(z)}(\mathrm{Pa})$ at a level close to $65 \mathrm{hPa}$ for each model, which is obtained by integrating the spacetime spectra with respect to $\omega$ from (upper left) 0.1 to $0.3 \mathrm{cpd}$, (upper right) 0.3 to $0.97 \mathrm{cpd}$, (lower left) 0.97 to $1.03 \mathrm{cpd}$, and (lower right) 1.03 to $4 \mathrm{cpd}$. Only positive (negative) values are shown for westward-moving (eastward-moving) disturbances. Because the lower-left panel is intended to show the contribution of the diurnal tides to $F^{(z)}$, models without the diurnal cycle are excluded.

Hagan et al. (1997) from satellite-observed brightness temperature data, using a method similar to that of RG2000. The magnitude of $F^{(z)}$ associated with the westward-moving nonmigrating tides is larger than that of the migrating tides in the lower stratosphere in all models (Fig. 7).

The diurnal tidal component of $F^{(z)}$ (lower-left panel of Fig. 8) has sharp peaks at westward $s=-5$ and eastward $s=+3$ at $65 \mathrm{hPa}$ in most models that have the solar diurnal cycle. This result is consistent with earlier studies (see section 1) and is explained by the significant wavenumber-4 component of land-sea distribution (i.e., $s=-1 \pm 4$; Tokioka and Yagai 1987). The diurnal signals of cumulus convection in the models are strong over the African and South American continents, and partly over the Maritime Continent. The former two are separated roughly by $90^{\circ}$, which corresponds to $|s|=4$. In FUB, the $s=+3$ peak does not exist, and the peak at $s=-5$ is weak, most likely because of the weak precipitation over South America (see Fig. 2). The $s=+3$ peak is also absent in ECHAM.

\section{3) Gravity waves}

The summation of $F^{(z)}$ attributed to the eastward-moving waves discussed above (the nonmigrating tides and planetary-scale Kelvin waves) explains only a small portion of the total $F^{(z)}$ due to eastward-moving disturbances except for the models with the ZM scheme. The 
remaining should mostly be attributed to nontidal gravity waves (including synoptic- or smaller-scale Kelvin waves). Nontidal westward-propagating gravity waves are also significant in the lower stratosphere of many models.

The wavenumber distribution of $F^{(z)}$ of subdiurnalfrequency disturbances (upper-right panel of Fig. 8) in the lower stratosphere have spectral slopes roughly close to -1 between $s=5$ and 20 for eastward-moving components in many models. This is also the case at the stratospause level (not shown). The slope of -1 indicates an equal partitioning along (logarithmically scaled) wavenumber. The slope is similar for westwardmoving components in the lower stratosphere, but wave elimination due to the mean easterly winds distorts it around the stratospause (not shown). Accordingly, $F^{(z)}$ above the upper stratosphere is dominated by tides.

Disturbances with superdiurnal frequencies (lowerright panel of Fig. 8) consist mostly of gravity waves including semidiurnal and higher-frequency tides. Most of the momentum flux at $65 \mathrm{hPa}$ is carried by waves with wavenumbers higher than 10. High-wavenumber components are especially significant in ECHAM, AGCM, and SKYHI, in which $F^{(z)}$ is relatively large.

\section{4) LATERALLY VERSUS VERTICALLY PROPAGATING WAVES}

Unlike $F^{(z)}$, the kinetic energy of the whole westwardmoving tides explains only a small portion of the kinetic energy of the whole westward-moving disturbances in all models. This is because a large portion of the kinetic energy is attributed to laterally propagating planetary waves (not shown). The contribution from vertically propagating waves in the kinetic energy increases with altitude, and it is dominant in the mesosphere in most cases. Typically, both planetary and gravity waves contribute significantly to the kinetic energy around the stratosphere.

\section{e. Driving force of the $S A O$}

Here, we investigate the SAO in the GCMs by examining the forcing from resolved waves. Note that in the models with nonorographic gravity wave parameterizations (ECHAM, UKMO, and MACCM) the forcing can also come from the parameterizations.

Figure 9 shows contributions from various wavenumber-frequency ranges of disturbances to the EP flux divergence over the latter half of January and the whole of February. At this time of year, westerly winds appear in the lower mesosphere and descend gradually to the upper stratosphere in observations (e.g., Garcia et al. 1997), with an maximum tendency of about $1 \mathrm{~m} \mathrm{~s}^{-1}$ day $^{-1}$. However, because of the easterly forcing due to the meridional circulation, the westerly eddy momentum deposition required is much larger than this value and may be as large as $4 \mathrm{~m} \mathrm{~s}^{-1} \mathrm{day}^{-1}$, as seen in the simulation by Sassi and Garcia (1997).

The EP flux divergence in half of the models (FUB, ECHAM, CMAM, and SKYHI-LR) shows positive peaks of $3 \mathrm{~m} \mathrm{~s}^{-1}$ day $^{-1}$ or larger in the lower mesosphere (Fig. 9). However, planetary-scale Kelvin waves contribute only small fractions in all of them. In particular, the $s=1$ Kelvin waves are negligible. From this result, it is clear why Amodei et al. (2001) found no relationship between $s=1$ Kelvin waves and the SAO in GCMs.

The waves contributing most to the westerly acceleration in the lower mesosphere differ among the four models (FUB, ECHAM, CMAM, and SKYHI-LR). In FUB, synoptic-scale disturbances ( $s \geq 4$ and $\omega<0.97$ ) dominate, with a secondary contribution from planetary-scale disturbances $(1 \leq s \leq 3$ and $\omega<0.3)$. In the other three models, there are significant contributions from disturbances with diurnal or higher frequencies as well as those with subdiurnal frequencies. In CMAM, the contribution from eastward-moving nonmigrating tides is the second largest, while in ECHAM it is minor and comparable to that from planetary-scale disturbances. The SAOs in FUB and SKYHI-LR were analyzed by Müller et al. (1997) and Hamilton and Mahlman (1988), respectively. Despite differences in analysis methods and periods, the results obtained here are roughly consistent with those studies. Medvedev and Klaassen (2001) obtained realistic stratopause and mesospheric SAOs using the CMAM with an additional nonorographic gravity wave parameterization. The stratopause SAO in their simulation was driven primarily by resolved waves, and the EP flux divergence they obtained is consistent with Fig. 9. Their mesospheric $\mathrm{SAO}$, on the other hand, is driven primarily by the nonorographic wave parameterization, which is absent in the CMAM studied here.

The EP flux divergence in MACCM, FVCCM, and UKMO does not show positive values in the lower mesosphere, suggesting that the westerly phases of the SAOs in MACCM and UKMO are driven mainly by parameterized gravity waves (Scaife et al. 2002 also showed it for UKMO). The peak EP flux divergence in MRI has a similar magnitude to that in the four models discussed earlier, but it is in the upper mesosphere, and the SAO is very weak (Fig. 1). From comparison with FUB, it appears that the reason why MRI has only a very weak SAO is at least partly because $\tilde{F}^{(z)}$ is weak for frequencies lower than $1 \mathrm{cpd}$.

The results obtained here are consistent with the studies that suggested that the role of planetary-scale Kelvin waves is minor in the SAO (section 1). In contrast, Sassi and Garcia (1997) reported that about half of the westerly forcing is attributed to planetary-scale waves. However, they used an idealized simulation in which waves are forced using a somewhat ad hoc "guidance" from observation, which may not necessarily be valid. The relative importance of resolved and unresolved waves 

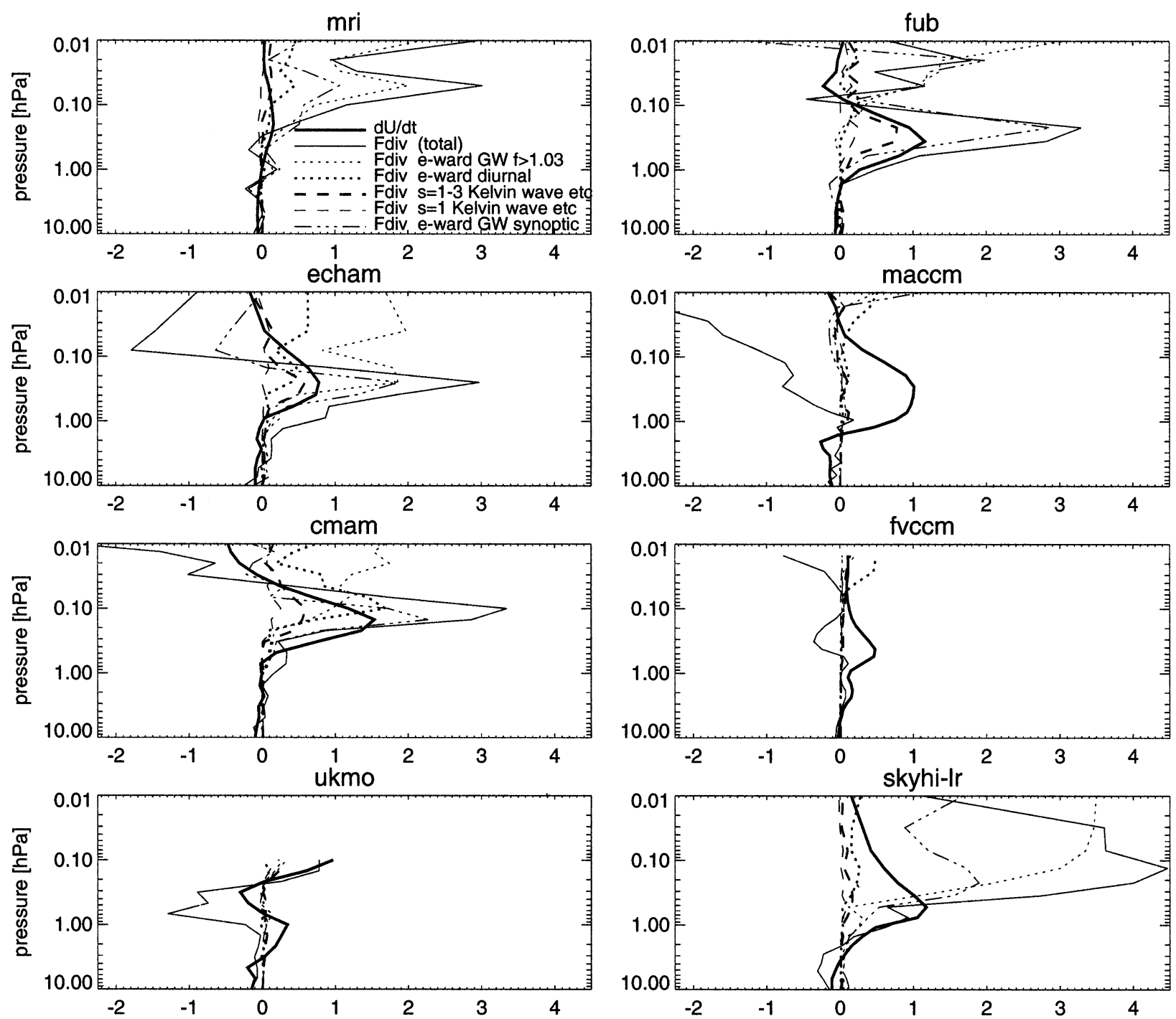

FIG. 9. EP flux divergence and the tendency of zonal wind averaged between $10^{\circ} \mathrm{N}$ and $10^{\circ} \mathrm{S}$ over the latter half of the DJF period (m s${ }^{-1}$ day $^{-1}$ ). The tendency is shown by thick-dashed lines, and the total divergence is shown by thin solid lines. Also shown are contributions to the divergence from various wavenumber-frequency ranges of eastward-moving disturbances: $1.03<\omega \leq 3$ cpd (thin-dotted lines; subdiurnal gravity waves), $0.97<\omega<1.03 \mathrm{cpd}$ (thick-dotted lines; nonmigrating diurnal tides), $s=1$ to 3 and $\omega<0.3 \mathrm{cpd}$ (thick-dashed lines; including planetary-scale Kelvin waves), $s=1$ and $\omega<0.2$ (thin-dashed lines; including $s=1$ Kelvin waves), and $s \geq 4$ and $\omega<$ 0.9 (synoptic-scale gravity waves).

in the SAO driving differs among the models, and what is the most realistic partitioning is difficult to judge.

\section{Conclusions}

Resolved waves in the equatorial middle atmosphere of nine GCMs were investigated in this study by using space-time Fourier analyses. Precipitation was examined as a proxy to the diabatic forcing of the waves. It was revealed that the overall variability of precipitation differs by more than one order of magnitude among models. The spectral shapes also have a large difference. The difference can mostly be explained by the use of different convective parameterizations. The classical
MCA scheme produces the largest variability, while the ZM and Gregory schemes produce the smallest variability, although they simulate a significant diurnal cycle in the precipitation over land. In addition to sharp peaks at the diurnal frequency and its higher harmonics, each cumulus parameterization produces broad spectral peaks at different frequencies (for instance at around $0.1 \mathrm{cpd}$ with the ZM scheme).

The fluctuating component of the cumulus convection dominates the generation of resolved waves that propagate into the equatorial middle atmosphere of the GCMs. In each model there is a remarkable correspondence between the space-time spectra of precipitation and lower stratospheric wave momentum flux. The cor- 
respondence is clear even throughout the middle atmosphere, except for waves that experience critical levels at lower altitudes. Since the spectra of precipitation are dominated by cumulus parameterization, we can conclude that the choice of cumulus parameterization has a profound impact on the vertically propagating waves in the equatorial middle atmosphere. Although the characteristics of cumulus parameterizations regarding wave excitation are of secondary importance in the modeling of tropospheric climate, this study suggests that they are very important to model the middle atmosphere climate. Note, however, that there are other factors that are important, especially regarding the propagation of the waves, as has been shown in past studies. For instance, vertical resolution is important both directly through its capability of resolving waves (Boville and Randel 1992) and indirectly by modifying environmental conditions (Nissen et al. 2000).

Although few observations exist for comparable analyses, it was suggested that the models with intermediate power in precipitation (ECHAM and MRI) may be the most realistic. Comparisons with observational estimates of $F^{(z)}$, which are very uncertain, yield a similar conclusion. The large overestimate of power in RG2000 led to the contradictory conclusion that the cumulus schemes that produce the largest power are most realistic, which is likely to be misleading.

Given that only models with the MCA scheme, which produced the highest precipitation variability, have simulated the QBO without gravity wave parameterization, the QBO in the atmosphere probably owes its forcing partly to subgrid-scale (or meso-scale) gravity waves. It is indicative that Giorgetta et al. (2002) showed that a newer version of the ECHAM model, which uses the same cumulus parameterization as the one investigated here, simulated a realistic QBO, which was driven roughly equally by resolved and parameterized waves.

In most models, planetary-scale eastward-moving disturbances including Kelvin waves account for onethird to one-half of the total kinetic energy of eastwardmoving disturbances in the stratosphere. As for $F^{(z)}$, however, the contribution of these disturbances is less than $10 \%$ in most cases. Parameterized cumulus convection excites nonmigrating tides with broad range of zonal wavenumber. Although the kinetic energy associated with nonmigrating tides accounts for only a small fraction of the total kinetic energy, in most models $F^{(z)}$ associated with eastward-moving nonmigrating tides is larger than that associated with planetary-scale Kelvin waves above $10 \mathrm{hPa}$, whose possibility has not been argued in literature. In terms of momentum transport, however, the most significant are nontidal gravity waves in most models. These waves are also the biggest contributors to kinetic energy in the mesosphere. The waves contributing to the driving of the simulated SAO are found to differ among models. However, in all models the role of planetary-scale Kelvin waves is fairly small. In particular, the contribution of the $s=1$ ultrafast
Kelvin wave is negligible. The SAO is driven mainly by gravity waves with periods less than 3 days (especially less than 1 day in many cases) and/or parameterized nonorographic gravity waves.

The present study has focused on comparison between several free-running models under conditions that are similar but not identical. It could be argued that this approach does not provide a controlled environment for the assessment of impacts of any particular parameterization. An ideal experimental framework for such study could be to run a single model under multiple realizations, each using a different cumulus parameterization scheme. While this would clearly allow controlled experiments, an additional consideration is the degree of feedback between different components of the climate system and their representation in models. Replacing a major component of the atmospheric system has considerable impacts on the simulated climate. Despite the lack of absolute rigor, the choice of using a well-validated ensemble of models for this type of experiment is therefore valid.

The present study has quantified resolved waves in various middle atmospheric GCMs, mainly in terms of the momentum flux. However, the comparison with observations is not thorough because of the limited coverage of observation and the difficulty in measuring vertical winds. More observations are needed to further assess GCMs and improve their physical basis.

Acknowledgments. The authors thank Drs. Lucrezia Ricciardulli for providing the data of diabatic heating spectra, Charles McLandress for carefully reading the manuscript and giving helpful comments, John Scinocca for discussions, and the anonymous reviewers. Takeshi Horinouchi's contribution to this work was supported by the JSPS Grant-in-Aid 11219203 and 13740278 . He also thanks Drs Toshitaka Tsuda and Shigeo Yoden for their support to this work. Steven Pawson's contribution was supported by the DAO and by NASA Grant GESTNCC5-494. E. Manzini and M. Giorgetta's contributions were supported by the BMBF projects MEDEC and KODYACS.

\section{APPENDIX A}

\section{Spectral Calculation}

The spectra shown in this paper were first calculated two-dimensionally with respect to zonal wavenumber $s$ and frequency $\omega$ by using the fast Fourier transform after subtracting mean values and applying a tapering with respect to time. They are one-sided with frequency so that a power spectrum $P(s, \omega)$ of a quantity $q(\lambda, t)$ is normalized to satisfy

$$
\frac{1}{2 \pi T} \int_{0}^{2 \pi} \int_{t_{0}}^{t_{0}+T}\left|q^{2}\right| d t d \lambda=\sum_{s=-N / 2}^{N / 2} \sum_{j=0}^{j_{\max }} P\left(s, \omega_{j}\right) \Delta \omega,
$$


where $t$ is time, $\lambda$ is longitude (in radians), $T$ is the period of the data, $\Delta \omega \equiv 1 / T$ (in cpd in this study), $t_{0}$ is the start time, $s$ is zonal wavenumber, $\omega$ is frequency, and $N$ is the number of grid points with longitude. When the spectrum is shown in the "energy-content" form (Fig. 4), it is multiplied by $s$ and $\omega$, so its units become equal to that of $\left|q^{2}\right|$. Note that the energy-content form is desirable to assess the relative importance of different wavenumber and/or frequency ranges. This is because it is practical to compare wavenumber-frequency ranges in a logarithmic interval such as $s=1$ through 3 versus $s=100$ through 300 , not versus $s=101$ to 103 .

The zonal wavenumber-frequency distribution of the vertical component of the EP flux, $\tilde{F}^{(z)}(s, \omega)$, is calculated from cross spectra as

$$
\begin{array}{r}
\tilde{F}^{(s)}(s, \omega) \equiv \alpha \rho_{0} \cos \phi \operatorname{Re}\left[Z \hat{v}(s, \omega) \hat{\theta}^{*}(s, \omega)\right. \\
\left.-\hat{u}(s, \omega) \hat{w}^{*}(s, \omega)\right], \\
Z \equiv\left[f-(a \cos \phi)^{-1}(\bar{u} \cos \phi)_{\phi}\right] \bar{\theta}_{z}^{-1} .
\end{array}
$$

Here, an asterisk denotes the complex conjugate; $\hat{u}, \hat{v}$, $\hat{w}$, and $\hat{\theta}$ are the Fourier coefficients of zonal, meridional and vertical velocities, and potential temperature; $\phi$ is latitude; $f$ is the Coriolis parameter; $a$ is the earth's radius; and $\alpha$ is the normalization constant for squared absolute values of Fourier coefficients [so as to satisfy Eq. (A1)]. The mean potential temperature $\bar{\theta}$ and zonal wind $\bar{u}$ are obtained by zonally and temporally averaging them over the period used for the spectral calculation. The log-pressure density $\rho_{0}$ is defined by $\rho_{s} p / p_{s}$, where $p$ is pressure; $\rho_{s}$ and $p_{s}$ are constant reference density and pressure, respectively; and $\rho_{s} / p_{s}$ is set to be $10^{-5} \mathrm{~s}^{2} \mathrm{~m}^{-2}$.

For line and two-dimensional plotting, spectra were smoothed by applying several passages of a 1-2-1 smoothing filter. The number of passages is greater for larger wavenumbers and frequencies. The filtering is only to improve presentation, so it is not applied, for example, with frequency when the spectra were divided in terms of frequency ranges as in Fig. 8.

\section{APPENDIX B}

\section{Discussion on Cumulus Parameterization}

We discuss here the cumulus parameterizations used in the models investigated in this study in terms of wave excitation. Table B1 summarizes the parameterizations. Many of them are mass flux schemes whose closure are based on convective available potential energy (CAPE), or the cloud work function, which is interpreted as a generalized CAPE. Exceptionally, the Gregory scheme in the UKMO model uses the buoyancy of a parcel at one level above the cloud base in which the parcel originates; convection is initiated if it is buoyant. In most of the CAPE-based mass flux schemes (ZM and Arakawa-Schubert schemes) deep convection is initiated, or "triggered," if CAPE is positive so as to realize quasi equilibrium. Unlike the original Tiedtke (1989) scheme, the Tiedtke/Nordeng scheme used in ECHAM is closed by CAPE (Nordeng 1994). In addition, it requires a positive large-scale moisture supply to initiate the deep convection, as in the original scheme and the Kuo scheme. All of the mass flux schemes examined here have parameterized convective downdraft. Some of the schemes include parameterizations of shallow or midlevel convection (see the table). The ZM scheme supports only deep convection, but in the CCMs, the Hack (1994) scheme is applied after the ZM scheme in order to cover midlevel convection, while the CMAM does not have such a scheme. All the models have large-scale condensation, which removes grid-scale supersaturation.

As has been shown in this study as well as in RG2000, the temporal variability of cumulus convection produced by the ZM scheme is fairly small. Guang and Guo (2001) attributed this to the lack of a mechanism to inhibit convection (deep convection is initiated whenever CAPE is positive). Then, the result that the Tiedtke/ Nordeng scheme produced relatively large variability may be explained by its requirement of positive largescale moisture supply, which works to inhibit (or, conversely, trigger) convection. We can further speculate that the similarity in the precipitation spectra in FUB and ECHAM (see Fig. 4) may be due to the similarity in this mechanism. It is not clear why the ArakawaSchubert scheme produced slightly larger variability than the ZM scheme. It is also noteworthy that the continuous peak with frequency is around $0.1 \mathrm{cpd}$ with the ZM scheme, while it is around $1 \mathrm{cpd}$ with the ArakawaSchubert scheme. These differences might be due to differences in details of the cloud models employed. For instance, Maloney and Hartmann (2001) suggested that the treatment of convective downdraft impacts the simulation of Madden-Julian oscillation.

Although both CMAM and the CCMs use the ZM scheme, the variability of precipitation is larger in the CCMs than in CMAM. The difference might be because only the CCMs have a parameterization of midlevel convection. Also, there is a difference in the value of a tunable parameter between the two models, which might affect the variability (J. Scinocca 2001, personal communication; the relaxation time of CAPE is different in the two). In UKMO, which use the Gregory scheme, the power of precipitation is as small as that produced by the ZM scheme, but it is enhanced significantly at high frequencies greater than $1.5 \mathrm{cpd}$ (see Fig. 5). This is not attributed to aliasing, since the data were averaged over the 3 -h time interval. It might rather be explained by the closure of the scheme mentioned above.

The MCA scheme has a tunable parameter on the relative humidity toward which the adjustment is conducted. The original formulation by Manabe et al. (1965) corresponds to setting the parameter, say $\gamma$, equal to $1(100 \%)$. By using a single-column test, Krishnamurti et al. (1980) showed that MCA with $\gamma=1$ pro- 
TABLE B1. Summary of cumulus parameterizations in the models with a focus on deep convection. For shallow and midlevel convection parameterizations, only their inclusion is recorded (third column). CWF and $q$ represent the cloud work function and moisture, respectively.

\begin{tabular}{|c|c|c|c|c|c|}
\hline Model & Method & $\begin{array}{l}\text { Shallow/ } \\
\text { midlevel }\end{array}$ & $\begin{array}{l}\text { Mass } \\
\text { flux? }\end{array}$ & Closure & Trigger \\
\hline MRI & Prognostic Arakawa-Schubert & Included & Yes & CWF & $\mathrm{CWF}>0$ \\
\hline FUB & Kuo & Tiedtke (1988) & No & $q$ supply & $q$ supply $>0$ \\
\hline ECHAM & Tiedtke & Included & Yes & CAPE & $q$ supply $>0$ etc. \\
\hline UKMO & Gregory & Included & Yes & (See the text) & (See the text) \\
\hline CMAM & $\mathrm{ZM}$ & None & Yes & CAPE & $\mathrm{CAPE}>0$ \\
\hline FVCCM/MACCM & $\mathrm{ZM}$ & Hack (1994) & Yes & CAPE & $\mathrm{CAPE}>0$ \\
\hline SKYHI & MCA & None & No & Stability & $\Gamma_{m} \lesssim 0$ \\
\hline AGCM & $\mathrm{MCA}$ & None & No & Stability & $\Gamma_{m} \lesssim 0$ \\
\hline
\end{tabular}

duced too much precipitation, with a mean precipitation closest to observations with $\gamma=0.82$. They also showed that the Kuo scheme (with similar configuration to that used in FUB) reproduced observational precipitation much better than MCA with $\gamma=0.82$, but no difference in the variance of precipitation can be inferred from their figures. The values of $\gamma$ used in the two models with the MCA scheme is 0.85 in the SKYHI models and 0.99 in AGCM. Contrary to the single-column results, even SKYHI produced the variability of precipitation much larger than that in FUB, while the difference between SKYHI and AGCM is small. This indicates a limitation of single-column experiments in which cumulus convection does not interact with large-scale dynamics. The precipitation obtained with MCA schemes in free-running models is dominated by gridscale pulses in the Tropics, which is not necessarily realistic.

\section{REFERENCES}

Amodei, M., S. Pawson, A. A. Scaife, U. Langematz, W. Lahoz, D. M. Li, and P. Simon, 2001: The SAO and Kelvin waves in the EuroGRIPS GCMS and the UK Met. Office analyses. Ann. Geophys., 19, 99-114.

Arakawa, A., and W. H. Schubert, 1974: Interaction of a cumulus ensemble with the large-scale environment, Part I. J. Atmos. Sci., 31, 674-701.

Baldwin, M. P., and Coauthors, 2000: The quasi-biennial oscillation. Rev. Geophys., 39, 179-229.

Beagley, S. R., J. de Grandpré, J. N. Koshyk, N. A. McFarlane, and T. G. Shepherd, 1997: Radiative-dynamical climatology of the first-generation Canadian Middle Atmosphere Model. Atmos.Ocean, 35, 293-331.

Boville, B. A., and W. J. Randel, 1992: Equatorial waves in a stratospheric GCM: Effects of vertical resolution. J. Atmos. Sci., 49, 785-801.

Cullen, M. J. P., 1993: The unified forecast climate model. Meteor. Mag., 122, 81-94.

Dunkerton, T. J., 1997: The role of gravity waves in the quasi-biennial oscillation. J. Geophys. Res., 102, 26 053-26 076.

Garcia, R. R., T. J. Dunkerton, R. S. Lieberman, and R. A. Vincent, 1997: Climatology of the semiannual oscillation of the tropical middle atmosphere. J. Geophys. Res., 102, $26019-26032$.

Giorgetta, M. A., E. Manzini, and E. Roeckner, 2002: Forcing of the quasi-biennial oscillation from a broad spectrum of atmospheric waves. Geophys. Res. Lett., 29, 1245, doi:10.1029/ 2002GL014756.

Gregory, D., and P. R. Rowntree, 1990: A mass flux convection scheme with representation of cloud ensemble characteristics and stability-dependent closure. Mon. Wea. Rev., 118, 1483-1506.

Guang, J.-Z., and M.-M. Guo, 2001: Preliminary evaluation of a revised Zhang-McFarlane convection scheme using the NCAR CCM3 GCM. Adv. Atmos. Sci., 18, 710-717.

Hack, J. J., 1994: Parameterization of moist convection in the National Center for Atmospheric Research Community Climate Model (CCM2). J. Geophys. Res., 99, 5551-5568.

Hagan, M. E., J. L. Chang, and S. K. Avery, 1997: Global-scale wave model estimates of nonmigrating tidal effects. J. Geophys. Res., 102, $16439-16452$.

Hamilton, K., 1981: Latent heat release as a possible forcing mechanism for atmospheric tides. Mon. Wea. Rev., 109, 3-17.

__ _ and J. D. Mahlman, 1988: General circulation model simulation of the semiannual oscillation of the tropical middle atmosphere. J. Atmos. Sci., 45, 3212-3235.

_, R. J. Wilson, J. D. Mahlman, and L. J. Umscheid, 1995: Climatology of the SKYHI troposphere-stratosphere-mesosphere general circulation model. J. Atmos. Sci., 52, 5-43.

,-- , and R. S. Hemler, 2001: Spontaneous stratospheric QBOlike oscillations simulated by the GFDL SKYHI general circulation model. J. Atmos. Sci., 58, 3271-3292.

Hertzog, A., and F. Vial, 2001: A study of the dynamics of the equatorial lower stratosphere by use of ultra-long-duration balloons. 2. Gravity waves. J. Geophys. Res., 106, 22 745-22 761.

Hitchman, M. H., and C. B. Leovy, 1988: Estimation of Kelvin wave contribution to the semiannual oscillation. J. Atmos. Sci., 45, 1462-1475.

Holton, J. R., 1975: The Dynamic Meteorology of the Stratosphere and Mesosphere. Meteor. Monogr., No. 37, Amer. Meteor. Soc., $216 \mathrm{pp}$.

—_, and R. S. Lindzen, 1972: An updated theory for the quasibiennial cycle of the tropical stratosphere. J. Atmos. Sci., 29, 1076-1080.

__ and W. M. Wehrbein, 1980: A numerical-model of the zonal mean circulation of the middle atmosphere. Pageoph, 118, 284306.

Horinouchi, T., 2002: Mesoscale variability of tropical precipitation: Validation of satellite estimates of wave forcing using TOGA COARE radar data. J. Atmos. Sci., 59, 2428-2437.

__ and S. Yoden, 1998: Wave-mean flow interaction associated with a QBO-like oscillation simulated in a simplified GCM. $J$. Atmos. Sci., 55, 502-526.

_, F. Sassi, and B. Boville, 2000: Synoptic-scale Rossby waves and geographic distribution of lateral transport routes between the Tropics and the extratropics in the lower stratosphere. $J$. Geophys. Res., 105, 26 579-26 592.

Huffman G. J., and Coauthors, 1997: The Global Precipitation Climatology Project (GPCP) combined precipitation dataset. Bull. Amer. Meteor. Soc., 78, 5-20.

Kiehl, J. T., J. J. Hack, G. B. Bonan, B. A. Boville, D. L. Williamson, and P. J. Rasch, 1998: The National Center for Atmospheric Research Community Climate Model: CCM3. J. Climate, 11, 1131-1149. 
Krishnamurti, T. N., Y. Ramanathan, H.-L. Pan, R. J. Pasch, and J. Morinari, 1980: Cumulus parameterization and rainfall rates I. Mon. Wea. Rev., 108, 465-472.

Kuo, H. L., 1974: Further studies of the parameterization of the influence of cumulus convection on the large-scale flow. J. Atmos. Sci., 31, 1232-1240.

Langematz, U., 2000: An estimate of the impact of observed ozone loss on stratospheric temperature. Geophys. Res. Lett., 27, 20772080.

Lin, S. J., 1997: A finite-volume integration method for computing pressure gradient forces in general vertical coordinates. Quart. J. Roy. Meteor. Soc., 123, 1749-1762.

__ and R. B. Rood, 1997: An explicit flux-form semi-Lagrangian shallow-water model on the sphere. Quart. J. Roy. Meteor. Soc., 123, 2477-2498.

Lindzen, R. S., 1978: Effect of daily variations in cumulonimbus activity on the atmospheric semidiurnal tide. Mon. Wea. Rev., 106, 526-533.

Maloney, E. D., and D. L. Hartmann, 2001: The sensitivity of intraseasonal variability in the NCAR CCM3 to changes in convective parameterization. J. Climate, 14, 2015-2034.

Manabe, S., J. Smagorinsky, and R. F. Strickler, 1965: Simulated climatology of a general circulation model with a hydrological cycle. Mon. Wea. Rev., 93, 769-798.

Manzini, E., N. A. McFarlane, and C. McLandress, 1997: Impact of the Doppler spread parameterization on the simulation of the middle atmosphere circulation using the MAECHAM4 general circulation model. J. Geophys. Res., 102, 25 751-25 762.

Medvedev, A. S., and G. P. Klaassen, 2001: Realistic semiannual oscillation simulated in a middle atmosphere general circulation model. Geophys. Res. Lett., 28, 733-736.

Miyahara, S., Y. Yoshida, and Y. Miyoshi, 1993: Diurnal coupling of the lower and upper atmosphere by tides and gravity waves. J. Atmos. Terr. Phys., 55, 1039-1053.

Müller, K. M., U. Langematz, and S. Pawson, 1997: The stratopause semiannual oscillation in the Berlin troposphere-stratospheremesosphere GCM. J. Atmos. Sci., 54, 2749-2759.

Nissen, K. M., P. Braesicke, and U. Langematz, 2000: QBO, SAO, and tropical waves in the Berlin TSM GCM: Sensitivity to radiation, vertical resolution, and convection. J. Geophys. Res., 105, 24 771-24 790.

Nordeng, T. E., 1994: Extended versions of the convective parameterization scheme at ECMWF and their impact on the mean and transient activity of the model in the Tropics. ECMWF Tech. Memo. 206, 41 pp.

Numaguti, A., 1993: Dynamics and energy balance of the Hadley circulation and the tropical precipitation zones-Significance of the distribution of evaporation. J. Atmos. Sci., 50, 1874-1887.

Pawson, S., U. Langematz, G. Radek, U. Schlese, and P. Strauch, 1998: The Berlin troposphere-stratosphere-mesosphere GCM: Sensitivity to physical parameterizations. Quart. J. Roy. Meteor. Soc., 124, 1343-1371.
- , and Coauthors, 2000: The GCM-Reality Intercomparison Project for SPARC (GRIPS): Scientific issues and initial results. Bull. Amer. Meteor. Soc., 81, 781-796.

Ray, E. A., M. J. Alexander, and J. R. Holton, 1998: An analysis of the structure and forcing of the equatorial semiannual oscillation in zonal wind. J. Geophys. Res., 103, 1759-1774.

Ricciardulli, L., and R. R. Garcia, 2000: The excitation of equatorial waves by deep convection in the NCAR Community Climate Model (CCM3). J. Atmos. Sci., 57, 3461-3487.

Salby, M. L., and R. R. Garcia, 1987: Transient response to localized episodic heating in the Tropics. Part I: Excitation and short-time near field behavior. J. Atmos. Sci., 44, 458-498.

Sassi, F., and R. R. Garcia, 1997: The role of equatorial waves forced by convection in the tropical semiannual oscillation. J. Atmos. Sci., 54, 1925-1942.

Sato, K., and T. J. Dunkerton, 1997: Estimates of momentum flux associated with equatorial Kelvin and gravity waves. J. Geophys. Res., 102, 26 247-26 261.

Scaife, A. A., N. Butchart, C. D. Warner, D. Stainforth, W. Norton, and J. Austin, 2000: Realistic quasi-biennial oscillations in a simulation of the global climate. Geophys. Res. Lett., 27, 34813484.

$\_, \ldots, \ldots$, and R. Swinbank 2002: Impact of a spectral gravity wave parameterization on the stratosphere in the Met Office Unified Model. J. Atmos. Sci., 59, 1473-1489.

Shibata, K., H. Yoshimura, M. Ohizumi, M. Hosaka, and M. Sugi, 1999: A simulation of troposphere, stratosphere and mesosphere with an MRI/JMA98 GCM. Pap. Meteor. Geophys., 50, 15-53.

Takahashi, M., 1996: Simulation of the stratospheric quasi-biennial oscillation using a general circulation model. Geophys. Res. Lett., 23, 661-664.

_ 1999 : Simulation of the quasi-biennial oscillation in a general circulation model. Geophys. Res. Lett., 26, 1307-1310.

Tiedtke, M., 1989: A comprehensive mass flux scheme for cumulus parameterization in large-scale models. Mon. Wea. Rev., 117, 1779-1800.

— W. W. Heckley, and J. Slingo, 1988: Tropical forecasting at ECMWF-The influence of physical parameterization on the mean structure of forecasts and analyses. Quart. J. Roy. Meteor. Soc., 114, 639-664.

Tokioka, T., and I. Yagai, 1987: Atmospheric tides appearing in a global atmospheric general circulation model. J. Meteor. Soc. Japan, 65, 423-438.

Williams, C. R., and S. K. Avery, 1996: Diurnal nonmigrating tidal oscillations forced by deep convective clouds. J. Geophys. Res., 101, 4079-4092.

Williamson, D. L., and J. G. Olson, 1994: Climate simulations with a semi-Lagrangian version of the NCAR Community Climate Model. Mon. Wea. Rev., 122, 1594-1610.

Zhang, G. J., and N. A. McFarlane, 1995: Sensitivity of climate simulations to the parameterization of cumulus convection in the Canadian Climate Center General-Circulation Model. Atmos.Ocean, 33, 407-446. 